\title{
WestVirginiaUniversity
}

THE RESEARCH REPOSITORY @ WVU

Graduate Theses, Dissertations, and Problem Reports

2012

\section{Identifying Potential Sources of Variation in Residual Feed Intake in Beef Cattle}

Kevin S. Shaffer

West Virginia University

Follow this and additional works at: https://researchrepository.wvu.edu/etd

\section{Recommended Citation}

Shaffer, Kevin S., "Identifying Potential Sources of Variation in Residual Feed Intake in Beef Cattle" (2012). Graduate Theses, Dissertations, and Problem Reports. 3591.

https://researchrepository.wvu.edu/etd/3591

This Dissertation is protected by copyright and/or related rights. It has been brought to you by the The Research Repository @ WVU with permission from the rights-holder(s). You are free to use this Dissertation in any way that is permitted by the copyright and related rights legislation that applies to your use. For other uses you must obtain permission from the rights-holder(s) directly, unless additional rights are indicated by a Creative Commons license in the record and/ or on the work itself. This Dissertation has been accepted for inclusion in WVU Graduate Theses, Dissertations, and Problem Reports collection by an authorized administrator of The Research Repository @ WVU.

For more information, please contact researchrepository@mail.wvu.edu. 


\title{
Identifying Potential Sources of Variation in Residual Feed Intake in Beef Cattle
}

\author{
Kevin S. Shaffer \\ Dissertation submitted to the \\ Davis College of Agriculture, Natural Resources, and Design \\ at West Virginia University \\ in partial fulfillment of the requirements \\ for the degree of
}

\section{Doctor of Philosophy in}

Animal and Food Science

\author{
Eugene E. D. Felton, Ph.D., Chair \\ Kimberly M. Barnes, Ph. D. \\ William Bryan, Ph. D. \\ E. Keith Inskeep, Ph.D. \\ Wayne R. Wagner, Ph.D. \\ Department of Animal and Nutritional Science
}

Morgantown, West Virginia

2012

Keywords: Residual Feed Intake, Beef Cattle, Metabolism, Rumen Function 


\title{
ABSTRACT
}

\section{Investigating Potential Sources of Variation in Residual Feed Intake in Beef Cattle}

\author{
Kevin S. Shaffer
}

Residual feed intake (RFI) class differences in gut function and grazing intake were evaluated using 14 crossbred steer progeny of first parity dams with known RFI phenotypes and a commercially available Angus sire. Steers were housed in a drylot facility and fed a forage based complete feed ad libitum, a forage diet at maintenance (1.5\% BW as fed), and a concentrate diet at maintenance in Exp. 1, 4, and 5 respectively. Voluntary DMI and solid and liquid passage rate were evaluated while grazing (Exp. 2 and 3, respectively). Plasma concentrations of albumin (ALB), urea nitrogen (UN), cholesterol (CHOL), glucose (GLU), triglycerides (TG), and VFA were assessed immediately pre- and at $3 \mathrm{~h}$ intervals for $12 \mathrm{~h}$ post-feeding as indicators of nutrient absorption in Exp. 1, 4, and 5 respectively. Rumen pH, ammonia $\left(\mathbf{N H}_{\mathbf{4}}\right)$, and VFA were evaluated $12 \mathrm{~h}$ post-feeding. Steers were classified as either positive (POS; $\mathrm{n}=8)$ or negative (NEG; $n=6$ ) according to dam RFI (mean $0.46 \mathrm{~kg}$ TND/d; range -4.27 to 5.70 $\mathrm{kg}$ TDN/d). Rumen $\mathrm{pH}$, ammonia, and VFA's did not differ based on RFI classification $(\mathrm{P}>0.05)$ in any of the experiments. Plasma metabolite and VFA concentrations did not differ between RFI classes in Experiment 1 ( $\mathrm{P}>0.05)$; however, UN was greater in POS (12.80 vs. $12.14 \mathrm{mg} / \mathrm{dL} ; \mathrm{P}=0.02)$ steers when fed a forage diet at maintenance (Exp. 4) and greater in NEG (16.74 vs. $15.42 \mathrm{mg} / \mathrm{dL}$; $\mathrm{P}=0.01)$ steers when fed a concentrate diet at maintenance (Exp 5). Plasma valerate and butyrate ( $\mathrm{P}=0.02$ and 0.02 , respectively) were greater in NEG steers in Exp. 1 and 5, respectively. Evaluation of RFI group differences by collection time revealed a significant $(\mathrm{P}=0.04)$ interaction of RFI and Time for TG and plasma isobutyric acid in Exp. 1. Concentrations of TG were greater ( $\mathrm{P}$ $=0.04$ ) in NEG steers at 3 hours after feeding but did not differ at any other time points. Plasma isobutyric acid concentrations rarely differed from zero but were greater in POS steers 6 hours post-feeding. The opposite was true at 12 hours post-feeding. No other interactions between RFI and collection time were significant. Negative RFI steers consumed numerically $8.9 \%$ less DM per day while grazing than POS steers but did not differ in voluntary DMI $(\mathrm{P}=0.74)$. Liquid passage rate was greater in NEG (7.16 vs. $6.32 \%$ marker/hour; $\mathrm{P}=0.04)$ steers but solid passage rate was not different $(\mathrm{P}=0.88)$. These data indicate that RFI classification may be associated with variation in the regulation and absorptive capacity of the gastrointestinal tract. 


\section{ACKNOWLEDGEMENTS}

I would like to take this opportunity to extend a heartfelt thanks and express my gratitude to all those who have assisted me in the completion of my graduate program. I am extremely grateful for the opportunities I have been provided here at West Virginia University, and I feel honored to have been able to complete my education in my home state.

Special thanks goes to Dr. Felton for the support and direction he has provided me during my graduate career. He generously allowed me to take my own path in pursuing my education and for that I am truly grateful. Your wealth of knowledge, experience, and continued support of production agriculture, particularly in West Virginia, is most admirable and you have my utmost respect. It has been an honor to work with you.

Additionally, I would also like to thank my committee members, Dr. Kimberly Barnes, Dr. William Bryan, Dr. Keith Inskeep, and Dr. Wayne Wagner for their guidance throughout my program. A special thank you goes to Dr. Wagner. Your wealth of knowledge and unique perspective about the beef industry has greatly enhanced my learning experience, challenged me to think outside the box and inspired me to pursue a career in extension.

I would be remiss if I did not extend thanks to my fellow graduate students, Nate Dean, Jennie Zambito and Todd Ramboldt, who not only contributed greatly to completion of my program but whom I also count as friends. I would also like to thank Mr. Eric Nestor for his continued assistance throughout my graduate program. 
Lastly, I would like to thank my family for the love and support they have provided me in all my endeavors. My parents have always instilled in me the belief that I could do anything, and for that, I am truly grateful. As well, I want to especially thank my wife, Monica, for her patience, love, and support as I continue my education and pursue my dreams. 


\section{TABLE OF CONTENTS}

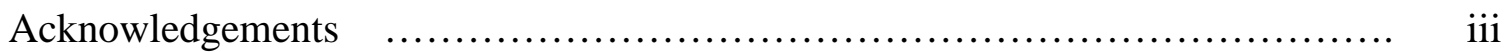

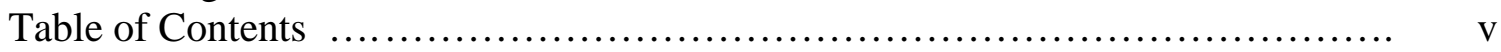

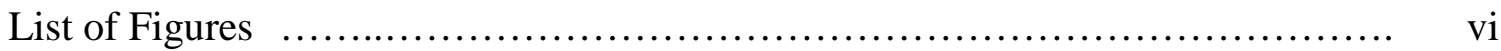

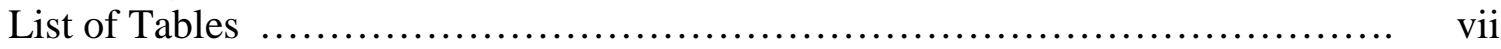

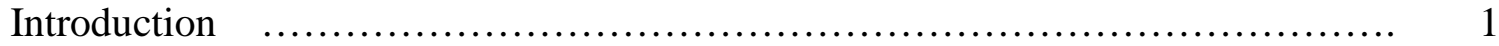

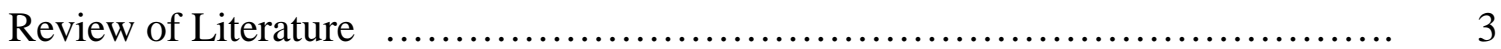

I. Measures of Efficiency-A Brief Overview ...................... 3

II. Residual Feed Intake ....................................... 6

a. An Overview: The Potential for Change .................. 6

b. $\quad$ Potential Problems: Test Environment .................... 9

c. Potential Problems: Test Timing ........................ 10

d. $\quad$ Potential Problems: Selection .............................. 11

III. Factors Affecting Residual Feed Intake ......................... 13

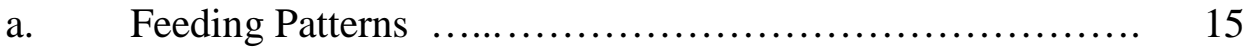

b. Body Composition ..................................... 16

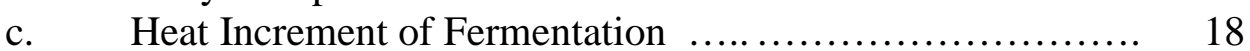

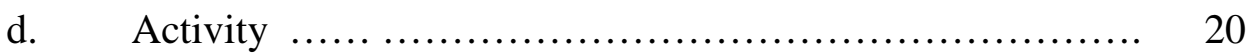

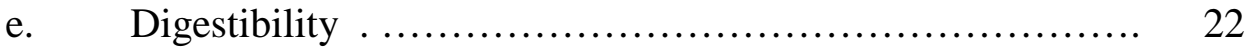

f. $\quad$ Protein Turnover, Tissue Metabolism and Stress $\ldots . . . . . . . . \quad 23$

V. Integration of Biological Mechanisms ......................... 26

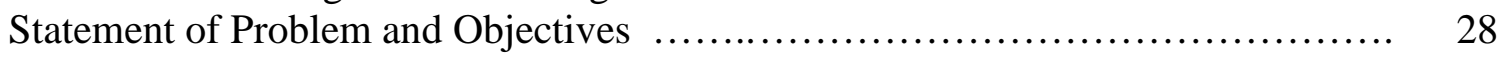

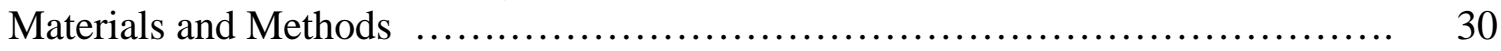

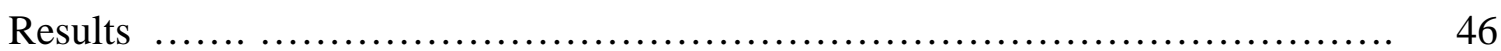

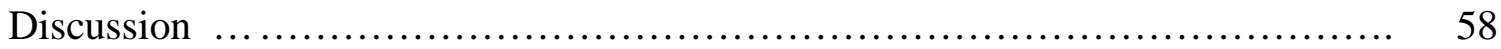

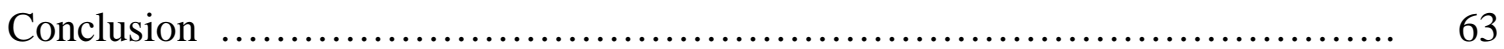

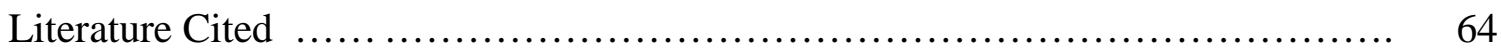

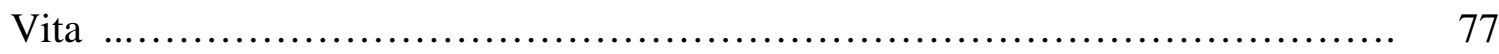

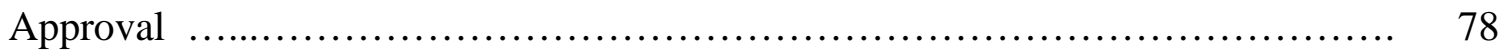




\section{LIST OF FIGURES}

Figure

Page

1. Contributions of biological mechanisms to variation in residual feed intake as determined from experiments on divergently selected cattle. Adapted from Richardson and Herd (2004)

2. Schematic of experimental procedures

3. Schematic representation of the grazing plots used in determination of grazing forage intake. Each triangular shaped portion represents a subplot, or the grazing allotment for one day. Sward height measurements were taken following transects represented by the dashed lines.

4. $\quad$ Figure 4. Plasma concentrations of triglycerides (A) and isobutyric acid (B) in steers immediately prior to feeding (Time 0 ) and at 3-hour intervals post-feeding (Times 3, 6, 9, and 12). 


\section{LIST OF TABLES}

Table

Page

1. Composition and nutrient analysis of diets for Experiment $1 . \ldots \ldots \ldots \ldots \ldots . . . . . .32$

2. $\quad$ Nutrient analysis of grazed forage for Experiments 2 and 3............... 37

3. Nutrient analysis of dietary components for Experiments 4 and 5. .......... 41

4. Descriptive statistics of steers entering Experiment $1 . \ldots \ldots \ldots \ldots \ldots \ldots \ldots \ldots$

5. Descriptive statistics of steers classified as POSITIVE or NEGATIVE RFI.. 47

6. Ultrasonic measures of body composition among POSTIVE and

NEGATIVE RFI steers.

7. Rumen $\mathrm{pH}$, ammonia, and volatile fatty acid concentrations among

POSITIVE and NEGATIVE RFI steers for Experiment 1.

8. Overall plasma metabolite and VFA concentrations in POSITIVE and

NEGATIVE RFI steers for Experiment 1.

50

9. Digesta rate of passage and voluntary dry matter intake while grazing in

POSITIVE and NEGATIVE RFI steers.

10. Phenotypic correlations between Dam RFI and measured traits in steer progeny for Experiments 2 and 3.

11. Rumen $\mathrm{pH}$, ammonia, and volatile fatty acid concentrations among

POSITIVE and NEGATIVE RFI steers for Experiment 4.

12. Overall plasma metabolite and VFA concentrations in POSITIVE and NEGATIVE RFI steers for Experiment 4.

13. Rumen $\mathrm{pH}$, ammonia, and volatile fatty acid concentrations among POSITIVE and NEGATIVE RFI steers for Experiment 5.

14. Overall plasma metabolite and VFA concentrations in POSITIVE and NEGATIVE RFI steers for Experiment 5. 


\section{INTRODUCTION}

Although the current state of the national and global economy is somewhat tumultuous, recent political and environmental conditions have created a pricing structure like that never before seen in the U.S. beef industry. With the nation's cow herd shrinking to 29.9 million (USDA NASS, 2012), a 50-year low, and the recent signing of several free trade agreements, national and international demand for beef is growing rapidly while supply remains relatively low. Thus, it would seem the opportunity for

profit is tremendous, yet margins remain relatively tight, particularly in the cattle feeding sector, as input costs continue to be extremely high.

According to the National Cattlemen’s Beef Association (Beef Industry Statistics, 2011), feedlot cost of gain has nearly doubled from an average of $\$ 261 /$ head from 19902003 to $\$ 494 /$ head over the last four years. In all, livestock producers are spending $\$ 45.2$ billion more on inputs in 2010 than they were in 2003 (USDA NASS, 2011), which can be primarily attributed to increased expenditures on feed and fuel. Of the $\$ 1.7$ billion increase in livestock production costs from 2009 to 2010, feed accounted for 41\% while fuel was responsible for $44 \%$. Thus, logic dictates a continued focus on managing and reducing input costs, particularly with respect to feed and fuel.

In modern beef production systems, approximately $70 \%$ of the total cost of beef production is directly related to feed costs (Herd et al., 1998; Liu et al., 2000). When considering breeding age females, around $70 \%$ of consumed feed energy is used solely for maintenance functions (Gregory, 1972; Ferrell and Jenkins, 1985a), indicating that around $50 \%$ of the total cost of production could be directly attributable to maintenance 
requirements. Therefore, reducing feed requirements, particularly those utilized for maintenance, becomes a necessary objective in developing a more profitable beef industry.

Fortunately, a growing body of literature provides evidence that residual feed intake (RFI), a measure of feed utilization efficiency, has the potential to reduce overall feed as well as maintenance requirements. Residual feed intake accounts for both maintenance and growth requirements and is widely accepted as the most useful measure of feed utilization efficiency. Due to the nature of RFI calculation, RFI should be indicative of individual differences in maintenance requirements; however, our long-term understanding of RFI remains somewhat limited and a large portion of the variation in RFI has yet to be explained (Richardson and Herd, 2004; Herd and Arthur, 2009). Thus, the focus of this literature review will be on our current knowledge of RFI, emphasizing relationships among production traits and known sources of variation in RFI. 


\section{LITERATURE REVIEW}

\section{MEASURES OF EFFICIENCY: A BRIEF OVERVIEW}

Livestock producers and researchers have long understood the overwhelming importance of production efficiency and have sought to identify ways by which efficiency could be measured and effectively improved through selective mating. Although production efficiency and overall profitability can be affected by a multitude of factors beyond reproduction and feed use, these factors have received the greatest research interest. In particular, feed use efficiency is of primary importance as over $70 \%$ of the total cost of production is directly related to feed costs (Herd et al., 1998; Liu et al., 2000). As a result, multiple methods for evaluation of efficiency have been developed and assessed as potential traits for selection.

As early as 1909, Kellner described feed use efficiency in livestock as the partial efficiency of growth (PEG), or the energetic efficiency of weight gain. Later, researchers revisited the concept while investigating ruminant energy metabolism and requirements for maintenance. Prominent researchers Klieber (1947) and Brody (1945) both developed independent measures of feed efficiency, namely Klieber ratio (KR) and feed conversion ratio (FCR). More recently, investigations by Koch et al. (1963) and Fitzhugh and Taylor (1971) reported alternative methods for evaluating the efficiency of feed use known as net feed efficiency or RFI and relative growth rate (RGR), respectively. Although each distinct method sought to more correctly evaluate feed use efficiency, industry adoption of a primary method for efficiency evaluation and selection 
was largely due to the ease of data collection and calculation. Consequently, FCR became the primary measure of feed utilization efficiency in ruminant livestock industries and in particular beef cattle.

Feed conversion ratio is calculated simply as feed consumed per pound of body weight gain (Brody, 1945); however, albeit simplistic in nature, there is error associated with both calculation and selection for FCR. Often, calculation of FCR is based upon an average or predicted feed intake value and does not account for individual animal variation in feed intake. More importantly, FCR does not account for differences in maintenance requirements and is influenced by variation in growth and maturity patterns (Archer et al., 1999). Furthermore, selection for ratio traits results in phenotypic change that is biased toward the denominator trait (Gunsett, 1984) and is evidenced in reports by Archer et al. (1999) and Herd and Bishop (2000) that indicate selection for FCR can result in increased growth rate and mature size of breeding females. Together, these factors indicate that selection for FCR may actually increase maintenance requirements of the cow herd. As a result, researchers have sought to re-evaluate other available measures of feed utilization efficiency.

Unlike PEG and FCR, KR, RGR, and RFI account for differences in maintenance requirements by taking into account either body weight (BW) or metabolic body weight $\left(\mathrm{BW}^{0.75}\right)$; however, direct comparison of the validity of these measures of feed efficiency as selection criteria has only recently been investigated. In 2001, Arthur et al. compared all the aforementioned measures of efficiency to BW and gain performance in a postweaning performance test comprised of over 700 Charolais bulls. Residual feed intake was independent of BW and ADG while strong positive genetic and phenotypic 
correlations existed between ADG and both $\mathrm{KR}(\mathrm{r}=0.82$ and 0.83 , respectively) and RGR ( $r=0.71$ and 0.68 , respectively). Conversely, FCR exhibited a negative phenotypic and genetic relationship with ADG ( $r=-0.54$ and -0.46 , respectively) while PEG only exhibited a phenotypic correlation with ADG $(r=-0.14)$. Phenotypic correlations between BW and PEG, FCR, KR, and RGR were all significant but near zero. In a similar study utilizing hybrid steers and bulls, Nkrumah et al. (2004) reported comparable phenotypic correlations between ADG and all four measures of efficiency. Similar relationships were reported in populations of Angus, Charolais, Hereford, Limousin, and Simmental bulls (Berry and Crowley, 2012; Crowley et al., 2010) and in Limousin x Holstein heifers (Kelly et al., 2010a). Interestingly, Nkrumah and coworkers (2004) also reported that RFI, PEG, and FCR indicated that bulls were more efficient than steers while KR and RGR did not. Ultimately, the authors concluded that their findings may mean that KR and RGR, which account for differences in maintenance requirements, are unable to detect true differences in energetic efficiency. In conclusion, Nkrumah et al. (2004) indicated that RFI was the only measure of efficiency phenotypically independent of its component traits and unaffected by pretest environment. An analogous conclusion was made by Hoque and others (2009a) when comparing feed efficiency measures using 22,000 progeny records of Japanese Black cattle. Although genetic values were estimated for the traits listed, RFI was preferred over other measures of efficiency. 


\section{RESIDUAL FEED INTAKE}

\section{Overview: The Potential for Change}

In 1963, Koch et al. introduced the concept of net feed efficiency or RFI, an index of energetic efficiency combining estimates of both maintenance and growth requirements in the prediction of individual animal feed intake. The calculated or expected feed intake is compared to actual intake and efficiency is measured as the residual with negative values being more desirable. By definition, RFI is phenotypically and genetically (Arthur et al. 2001; Crowley et al., 2010) independent of its component traits (ADG and BW), so it allows comparison of individuals differing in level of production or gain. As such, RFI, being a residual, may represent inherent variation in basic metabolic processes (Herd and Arthur, 2009).

As an illustration, consider the estimate of maintenance requirements utilized in calculating RFI, metabolic body weight or $\mathrm{BW}^{0.75}$. This is a standard conversion applied to all animals in the test population and is the mean estimate of the collective works of Brody (1945), which was slightly different from that of Klieber (1947), who provided an estimate of $\mathrm{BW}^{0.73}$. An estimate of RFI accounts for observed differences in gain performance, so it is believed that RFI may actually represent individual animal variation in maintenance requirements relative to the standardized estimate. Based upon the reports of Brody (1945) and Klieber (1947), it is obvious that variation does exist around these conversion estimates of maintenance needs. In fact, Herd and Bishop (2000) observed that genetic variation in RFI was closely related $(r=0.93)$ to genetic variation in maintenance energy requirements per kilogram of metabolic body weight in Hereford 
bulls. Similarly, Luiting et al. (1991) reported that variation in maintenance energy expenditures were a major contributor to variation in RFI in laying hens. Since $70-75 \%$ of total metabolizable energy requirements for beef production are consumed solely for maintenance functions (Ferrel and Jenkins, 1985), the potential of RFI to identify animals that require less energy for maintenance and subsequently consume less feed is of significant economic importance.

Accordingly, considerable variation in feed intake above and below that predicted based on body weight and weight gain has been reported in mice (Archer et al., 1998), poultry (Byerly, 1941; Luiting and Urff, 1991), pigs (Foster et al., 1993; Gilbert et al., 2007; Hoque et al., 2007), and cattle (Archer et al., 1999). A genetic basis for this variation exists with estimates of the heritability of RFI ranging from 0.16 (Herd and Bishop, 2000) to 0.52 (Rolfe et al., 2011) with most falling in the range of 0.30 to 0.40 . Although a substantial portion of the additive genetic variation in RFI can be accounted for by phenotypic measurement and potentially even breed differences (Schenkel et al., 2004; Elzo et al., 2009; Rolfe et al., 2011), an even larger portion is due to other factors like qualitative genetic interactions, heterosis (Rolfe et al., 2011), and/or potentially genotype x environment interactions (i.e. non-additive genetic effects). Thus, selection for RFI to reduce feed intake and energetic requirements of livestock may result in less true genetic change than desired and animals that may actually gain weight less rapidly (Crowley et al., 2012).

Consequently, Crowley et al. (2012) has proposed utilizing RFI in combination with residual BW gain (RG) in an additive method or as components of a linear selection index for efficiency. By doing so, the authors suggest that only those animals that have 
increased performance with less than average feed intake will be identified as efficient. In a preliminary study of multiple breeds of beef bulls, the resulting heritability estimate (0.36) of the trait known as residual intake and BW gain (RIG) was equivalent to that of RFI itself, however, RIG was not independent ( $r=0.41$ ) of ADG (Crowley et al., 2012). Similarly, Rolfe et al. (2011) reported that selection for a linear index combining RFI and BW gain would result in the most positive economic outcome for growth and feed intake. Nonetheless, the collection of individual animal feed intake and RFI calculation is still necessary.

Although it is not without flaws, RFI is the most commonly used measure of feed efficiency in beef cattle performance tests today (Berry and Crowley, 2012), being independent of its component traits (Arthur et al., 2001a; Crowley et al., 2010) as well as mature size (Crews, 2005). When used as a component of a balanced trait selection program, it is believed that RFI has tremendous potential to reduce feed requirements of the beef herd without indirect selection effects on body composition, maturity, or fertility (Shaffer et al., 2011). Additionally, widespread adoption and utilization of RFI data by cattle producers, which seemed initially very slow, appears to be growing. A recent study by Wulfhorst et al. (2010) indicated that $49.1 \%$ of commercial producers were willing to select bulls on RFI and $43.6 \%$ of seedstock producers were willing to begin collecting RFI data. Furthermore, it is estimated that over 30,000 bulls will be offered for sale in 2012 with RFI data (Allison Sunstrum, GrowSafe Systesm, Ltd., personal communication). Nonetheless, long term selection effects and those factors responsible for variation in RFI are not yet well understood either practically or physiologically. 


\section{Potential Problems: Test Environment}

Our current knowledge of RFI is, at best, in its adolescence. It would be illogical to begin selecting for an index of efficiency containing a component trait that is not better understood and may not be acceptably repeatable across tests or diets. For example, Durunna et al. (2011a) compared growing steers over two consecutive 10-week feedintake trials with three dietary treatments. Steers were fed either a grower diet for both 10-week trials, a finisher diet for both 10-week trials, or a grower for the first 10 weeks and then switched to a finisher diet for the remaining 10 weeks. Comparing individual animal FCR, KR, and RFI classification ( $<0.5$ SD below the mean, \pm 0.5 SD around the mean, and $>0.5 \mathrm{SD}$ above the mean) across the trials and diets, the authors reported that $>50 \%$ of steers changed RFI group across all dietary treatments with those animals that changed from the grower to finisher diet exhibiting the greatest amount (58\%) of reranking. Even so, FCR and KR exhibited a greater amount of re-ranking from one feeding regimen to another while RFI maintained a similar proportion across all feeding regimens. Similar results were obtained in growing heifers receiving the same diet over two consecutive tests (Durunna et al., 2012).

Although not directly related to re-ranking potential, the data of Goonewardene et al. (2004), who evaluated optimum test duration for accurate RFI calculation over a variety of diets, reported that a shorter test duration was required (63 days) when feeding a 100\% forage diet, based upon correlations with RFI during shortened test periods with that of the whole (105 days). In contrast, when the diet consisted of 15\% barley grain, minimum test duration reached 84 days, indicating test duration may be dependent upon diet (Goonewardene et al., 2004). However, there is a larger body of evidence that test 
diet or environment (geographic or seasonal) is unlikely to affect test duration or accuracy (Archer et al., 1997; Archer and Bergh, 2000; Wang et al., 2005; Wang et al., 2006). Even though seasonal effects on RFI have been reported (Mujibi et al., 2010), they cannot be separated from age associated physiological changes in metabolism. Ultimately test duration is limited by the accurate assessment of weight gain (Shaffer, 2010), and it would be logical to assume that dietary effects on rate of weight gain may be partially responsible for the observations by Durunna et al. (2011a; 2012)

\section{Potential Problems: Test Timing}

To determine the optimum physiological time point for RFI testing to minimize the potential for feed efficiency re-ranking, researchers have utilized part-whole correlations to identify the strength of the relationship between measures obtained during one feeding period to the overall feed efficiency measure for the entire trial. Pearson correlation coefficients were significantly greater between the second period RFI and overall RFI than between the first period RFI and overall RFI in steers fed a grower ration ( $r=0.87 \mathrm{vs} 0.72$, respectively) or steers fed a grower ration followed by a finisher ration ( $r=0.83$ vs 0.74 , respectively) (Durunna et al., 2011a). No differences were reported in the group receiving the finisher diet. Similarly, Durunna et al. (2012) reported a numerically greater correlation between the second period RFI and overall RFI in growing heifers than between the first period RFI and overall RFI ( $r=0.77$ vs 0.84 ). These data are in agreement with Goonewardeene et al. (2004) and indicate that greater repeatability and accuracy of feed efficiency measures is achieved when animals are closer to maturity. Generally speaking, these data indicate a lower proportion of reranking with less energy dense diets, leading the authors to suggest the use of grower 
type rations for more accurate feed efficiency evaluation of breeding stock (Duranna et al., 2011a; Durunna et al., 2012).

Other authors have looked at the repeatability of RFI or correlation between test periods on the same population of animals without evaluating the potential for re-ranking. Arthur et al. (2001a) reported that RFI was highly correlated phenotypically $(r=0.85)$ and genetically $(r=0.95)$ when measured at 15 months of age and again at 19 months of age in Charolais bulls. Similarly, a strong phenotypic relationship $(r=0.74)$ was reported between post-weaning RFI and feed intake of the same cows measured at four years of age (Arthur et al., 2004). In contrast to these data and that discussed previously, Archer et al. (2002) reported only a moderate phenotypic correlation $(r=0.40)$ between postweaning and mature RFI. In partial agreement with this report, Herd et al. (2006) reported that repeatability of RFI from post-weaning to maturity was 0.39 . On the contrary, within animal repeatability has been reported to be greater (0.65) (Kelly et al., 2010b). It is important to note, however, that these measures were calculated during drastically different physiological states and physiological state is a major source of variation in maintenance energy requirements.

\section{Potential Problems: Selection}

Recent investigations relative to RFI and its potential relationships to other economically important traits in beef production have yielded some very interesting discoveries. From early on it became apparent that RFI was related to body composition in young growing cattle. In studies with ultrasonographic measures of body composition, there was almost always a significant yet moderate positive correlation between RFI and ultrasonographic back fat (UBF) regardless of sex (Richardson et al., 2001; Basarab et 
al., 2003; Schenkel et al., 2004; Nkrumah et al., 2007c; Lancaster et al., 2009a; Lancaster et al., 2009b; Kelly et al., 2010a; Shaffer et al., 2011). This relationship has been highly recognized in swine (Johnson et al., 1999; Nguyen et al., 2005; Hoque et al., 2007; Gilbert et al., 2007; Hoque et al., 2009b; Boddicker et al., 2011; Smith et al., 2011). Less frequently, RFI was related to lean tissue mass in cattle with the relationship sometimes being positive (Lancaster et al., 2009a; Lancaster et al., 2009b) and sometimes negative (Shaffer et al., 2011). In swine, it appears that this relationship is negative and observed more frequently (Johnson et al., 1999; Nguyen et al., 2005; Hoque et al., 2007; Hoque et al., 2009b; Smith et al., 2011). As a result, many authors have suggested including one or more measures of body composition, primarily UBF, into the model for calculating RFI and thereby forcing independence from these traits and making RFI a more robust measure of efficiency; however, widespread adoption of this methodology has not yet occurred (Richardson et al., 2001; Basarab et al., 2003; Schenkel et al., 2004; Nkrumah et al., 2007c; Cai et al., 2008; Arthur et al., 2009; Lancaster et al., 2009a; Lancaster et al., 2009b; Kelly et al., 2010a; Shaffer et al., 2011). This concept has been reviewed in greater detail by Shaffer (2010).

Other production traits such as hip height and scrotal circumference are not related to RFI (Arthur et al., 2001b; Basarab et al., 2003; Schenkel et al., 2004; Kelly et al., 2010a); however, initial anecdotal evidence of a relationship with age at puberty in first parity cows (Arthur et al., 2005; Basarab et al., 2007) and yearling heifers (Donoghue et al., 2011) has been observed. Upon further investigation, a relationship with age at puberty in yearling heifers was identified (Basarab et al., 2011; Shaffer et al., 2011). Negative RFI heifers were reported to reach puberty approximately two weeks 
later than their positive RFI contemporaries; however, no differences in overall conception rates were observed in either study. Interestingly, a greater percentage of positive RFI heifers (76 vs $62 \%$; $\mathrm{P}=0.04$ ) became pregnant during the first 21 days of the breeding season in the study by Basarab et al. (2011). Similar to the results in cattle, Gilbert et al. (2012) did not observe any differences in rebreeding performance of sows after seven generations of divergent selection for RFI. In a more detailed evaluation of the relationship between luteal function and RFI, Lents et al. (2011) did not observe a relationship between RFI and ovulatory response to luteal regression by injection of prostaglandin $\mathrm{F} 2_{\alpha}$. Together these data indicate that long term selection for lesser RFI may result in increasing age of sexual maturity, which could result in subsequent infertility during a defined breeding season. However, the physiological explanation for this relationship between RFI and sexual maturity has yet to be examined.

\section{FACTORS AFFECTING RESIDUAL FEED INTAKE}

Herd et al. (2004), Richardson and Herd (2004), and Herd and Arthur (2009) have previously reviewed and proposed five major processes by which variation in feed efficiency can arise. Feed intake, digestion, metabolism, activity, and thermoregulation were identified. After reviewing the available data, the authors identified six specific biological mechanisms and the proportion of variation in RFI for which each was responsible. These mechanisms and their respective proportion of variation in RFI are presented in Figure 1. Even after such a thorough review, a large proportion of the variation in RFI (27\%) has yet to be elucidated, serving as the basis for future inquiry. It 
is important to note that a significant portion of the data used to identify these proposed mechanisms was generated in non-ruminant species. As such, the data may indicate areas of interest, but may not be entirely accurate in their interpretation and/or application.

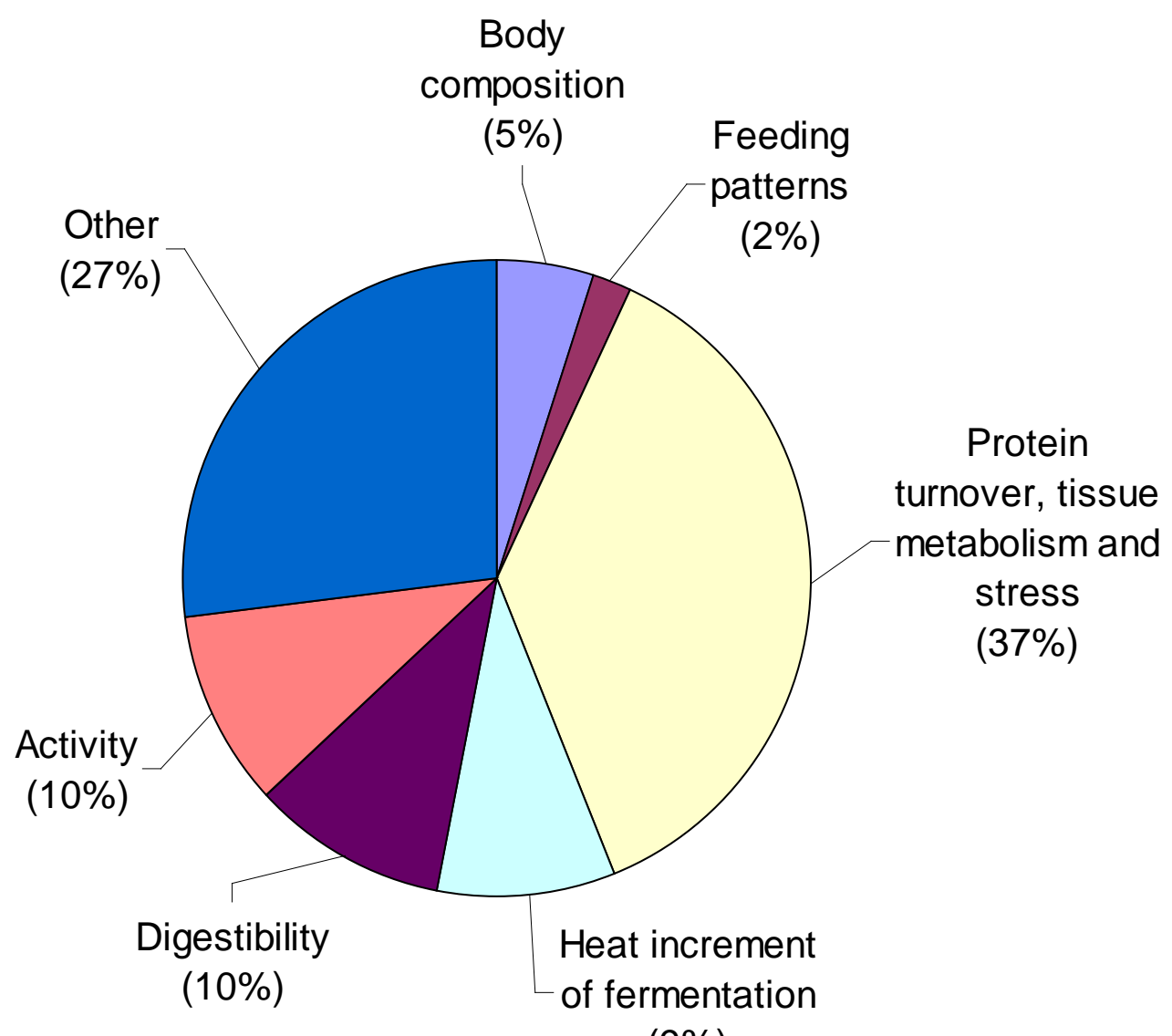

$(9 \%)$

Figure 1. Contributions of biological mechanisms to variation in residual feed intake as determined from experiments on divergently selected cattle. Adapted from Richardson and Herd (2004). 


\section{Feeding Patterns}

Eating rate and meal duration are key factors in determining the energy cost of eating in cattle (Adam et al., 1984), and are moderate to highly heritable across growing and finishing diets (Durunna et al., 2011b). In a report by Nkrumah et al. (2007b), high RFI steers fed more frequently (31.50 events/d) than low RFI steers (27.24 events/d) with medium RFI steers being intermediate (30.36 events/d). Additionally, RFI was positively correlated $(\mathrm{r}=0.49)$ with feeding duration. When evaluating growing heifers over two consecutive test periods, Durunna et al. (2012) reported that medium and low RFI heifers fed less frequently than high RFI heifers (98.03 and 96.36 events/d vs 110.09 events/d). This was true in a similar study using steers in a post-weaning test (Durunna et al., 2011b). Other reports indicate that this is also true in swine (Berea et al., 2010). In contrast, Bingham et al. (2009) did not report any association between RFI and feeding duration or frequency in Brangus heifers. However, high RFI heifers ate at a faster rate than their more efficient contemporaries (101.6 vs $62.4 \mathrm{~g} / \mathrm{min}$, respectively). Similarly, Kelly et al. (2010a) reported a positive correlation between RFI and both eating rate ( $\mathrm{r}=$ 0.26) and feeding events $(r=0.45)$ in Limousin X Holstein heifers. Although not statistically significant, a similar trend in feeding frequency was observed by Robinson and Oddy (2004) in both steers and heifers.

From synthesis of these reports, one could suggest that high RFI animals consume more feed by eating more frequently or at a faster rate when compared to low RFI animals; however, there is evidence that other factors may be involved. Spectral analysis of feeding patterns in Angus steers revealed that high RFI animals have a more variable temporal pattern of feed intake early during the test period, while low RFI steers quickly 
acclimated to a regular feed-intake cycle (Dobos and Herd, 2008). Nonetheless, the mechanisms controlling variation in feeding patterns are difficult to isolate (Richardson and Herd, 2004). The latter authors hypothesized, based on a review of the literature on voluntary intake, that animals do not consume feed at an amount or rate to meet the demands of genetically maximum production. In contrast, the reviewers believed that feed consumption is controlled by net energy requirements and that the concomitant consumption of oxygen is the cost of feed consumption, because the use of oxygen in metabolism indirectly causes damage to cell structures. Furthermore, the authors theorized that the effect of oxygen consumption and the resulting 'metabolic acid' load are regulated by optimizing the rate of lipid synthesis in adipose tissue. It is well established that high RFI animals have a larger volume of adipose tissue, so this would assist them in reducing the greater metabolic acid load associated with their greater feed intake. Although this may indicate a link between feeding patterns and body composition related to RFI, differences in feeding patterns account for only $2 \%$ of the known variation in RFI at present (Richardson and Herd, 2004).

\section{Body Composition}

The relationship between RFI and body composition in cattle has been reviewed (Richardson and Herd, 2004; Herd and Arthur, 2009) and is well established. In general, reports indicate that low RFI animals possess less fat and equal or more lean tissue mass than high RFI animals. Similar results have been obtained in swine (Herd and Arthur, 2009), in which backfat thickness was associated positively $(r=0.44)$ with genetic variation in RFI (Gilbert et al., 2007). In poultry, reports relating body composition to variation in RFI are quite variable. In a summary of genetic and phenotypic associations 
between measures of body fat and RFI in poultry, Luiting (1990) reported a range from -0.40 to 0.45 . Later, various reports on selection in poultry indicated that low RFI lines contained more fat than high RFI lines (Herd and Arthur, 2009). This trend, opposite to that observed in cattle and swine, also was reported in mice (Archer et al., 1998). Even so, no matter the direction of the relationship, body composition never accounted for more than 5\% of the variation in RFI (Herd and Arthur, 2009).

Although body composition typically references differences in lean, fat, and bone, differences in tissues as components or whole organ systems can affect maintenance requirements of livestock. For example, tissues of the splanchnic bed comprise around 15 to $20 \%$ of the total body mass in ruminants (Seal and Parker, 2000) and account for 35 to $60 \%$ of total oxygen consumption (Seal and Reynolds, 1993). Approximately $20 \%$ of consumed oxygen is utilized by the gastrointestinal tract (GIT) (Cant et al., 1996) with another 20.5\% being used by the liver (Eisemann and Nienaber, 1990). When comparing visceral organ mass and heat production of Angus steers divergently selected for RFI, Richardson et al. (2001) did not report an association with variation in RFI even though maintenance requirements are associated with visceral organ mass in beef cattle (Montano-Bermudez et al., 1990). In contrast, Nkrumah et al. (2006) reported that RFI was associated positively with methane and heat production $(r=0.44$ and 0.68 , respectively) and negatively with retained energy $(r=-0.67)$, indicating that differences in visceral organ mass may exist. Similar indirect evidence is available in swine in which low RFI pigs exhibited less fasting heat production than high RFI pigs (771 vs $846 \mathrm{~kJ} / \mathrm{kg}$ of BW${ }^{0.60} / \mathrm{d}$ ) (Berea et al., 2010). However, reports by Mader et al. (2009) and Cruz et al. (2010) found no differences in visceral organ mass due to RFI classification in cattle. 
Visceral tissues are enormous energy sinks, so the indirect evidence of associations with

RFI cited above may be indicative of individual variation in the efficiency of the processes of energy metabolism rather than the capacity of the tissue for energy metabolism.

\section{Heat Increment of Fermentation}

Energy in feedstuffs can be broken down into several categories based on the type and specific form in which energy components are consumed throughout the processes of digestion and metabolism; nonetheless, in order to be utilized, feed energy must be changed into a form usable by the animal. Lofgreen and Garrett (1968) described the feed energy that is usable by the animal as net energy, which can be used either for maintenance $\left(\mathrm{NE}_{\mathrm{m}}\right)$ or any productive process above maintenance $\left(\mathrm{NE}_{\mathrm{g}}\right)$ (i.e. gain). Analogous to a financial analysis of profit, net energy is the available energy (i.e. profit) after the cost of changing the gross feed energy into a form usable by the animal. Thus, it follows that the difference between net energy and gross energy was lost during the process of transformation. According to the First Law of Thermodynamics energy can neither be created nor destroyed, so logically the energy 'lost' in transformation must have changed form.

In ruminants, fermentation by rumenal bacteria of the energy yielding components of feed produce several products that can be utilized further by the host animal for energy (i.e. ammonia, bacterial cells, and volatile fatty acids) and some that cannot (heat, methane, carbon dioxide) (Blaxter, 1962). These byproducts of rumen fermentation not usable by the animal represent the energy forms lost in transformation. Of those, the heat of fermentation characterizes anywhere from 3 to $12 \%$ of the gross 
energy of the feedstuff (Blaxter, 1962), yet few studies have evaluated the relationship of RFI to energy losses as the result of fermentation.

In Angus steers with over 2 generations of divergent selection for RFI, high RFI steers produced 33.7\% more methane per day than their low RFI contemporaries (Hegarty et al., 2006). An earlier study by Okine et al. (2001) reported that low RFI cattle produced $21 \%$ less methane and $15 \%$ less manure on a yearly basis than high RFI groups. A similar comparison of enteric methane production by Herd et al. (2002) indicated that low RFI animals produced 15\% less methane per day than similar high RFI animals. Most recently, Muro-Reyes et al. (2011) evaluated RFI as a method to reduce methane production in sheep. Based on DMI in Rambouillet ewes and rams, low and medium RFI sheep produced significantly less methane per day than high RFI sheep (0.028 and $0.029 \mathrm{~kg} / \mathrm{d}$ vs. $0.033 \mathrm{~kg} / \mathrm{d}$, respectively; $\mathrm{P}<0.01)$. These data are in partial agreement with the study of Nkrumah et al. (2006), who used three RFI classifications while evaluating methane production in crossbred steers. In this study, low RFI steers produced significantly less methane than both the medium and high RFI groups (1.28 $\mathrm{L} / \mathrm{kg} \mathrm{BW}^{0.75}$ vs. 1.68 and $1.71 \mathrm{~L} / \mathrm{kg} \mathrm{BW}^{0.75}$, respectively; $\left.\mathrm{P}=0.04\right)$. Unlike the previous studies, Nkrumah et al. (2006) reported a positive correlation $(r=0.44)$ between RFI and daily methane production.

Reports in the literature relating RFI to heat production and energy loss during fermentation and digestion are difficult to find. To date, only one attempt to detail the relationship between differing RFI phenotypes and the heat increment of fermentation has been reported. In the same group of crossbred steers evaluated for methane emissions, Nkrumah et al. (2006) measured daily dietary energy flow. In this study, low 
RFI steers had significantly $(\mathrm{P}=0.02)$ more metabolizable energy $(\mathbf{M E}=$ [(gross energy - fecal energy) - urine/gas) than high RFI steers (265.73 vs. $238.54 \mathrm{kcal} / \mathrm{kg}$ of $\mathrm{BW}^{0.75}$ ) with the medium RFI group being intermediate $\left(248.73 \mathrm{kcal} / \mathrm{kg}\right.$ of $\left.\mathrm{BW}^{0.75}\right)$. Trending in the opposite direction, overall heat production was lowest $(\mathrm{P}<0.001)$ in low RFI steers and highest in the high RFI group. While not significant $(\mathrm{P}=0.58)$, low RFI steers exhibited a numerically lower heat increment of feeding than medium or high RFI groups (36.08 kcal/kcal of ME vs. 53.18 and $53.60 \mathrm{kcal} / \mathrm{kcal}$ of ME). Interestingly, urine and fecal energy loss or the ratio of ME to digestible energy (DE) as a percent of gross energy did not differ among RFI classifications, indicating that the ability to digest and absorb the diet was similar. However, methane energy loss as a percentage of gross energy differed based on RFI classification. In this case, low RFI steers lost significantly less energy to methane than the medium and high RFI classes (3.19\% vs. 4.25 and $4.28 \%$, respectively; $\mathrm{P}=0.04$ ) indicating that the different RFI classes may in fact have differing rumenal bacterial populations and efficiencies. This has been shown to be the case in lines of mice selected for low and high heat loss and differing in feed intake (Nielsen et al., 2009), but has yet to be reported in cattle relative to RFI.

\section{Activity}

Energy requirements of livestock are generally broken into the categories of maintenance and growth, but variation in energy requirements can be due to differing levels of activity. As RFI accounts for differences in maintenance and growth requirements, the energy required for general activity may represent an unaccounted for source of variation in the trait. To date, studies evaluating the effect of activity level on 
RFI have primarily focused on monogastric species with more recent evaluations utilizing ruminants.

Total daily feeding time and number of visits to a feeding station were positively correlated ( $r=0.64$ and 0.51 , respectively) with RFI in swine (de Haer et al., 1993). After 5 generations of selection in Yorkshire swine, Young et al. (2011) reported that low RFI pigs spent less time eating but ate faster. In a similar population of gilts, the low RFI line spent less time standing (13.72 vs. $15.21 \%$ of total time), more time sitting (2.50 vs. $2.12 \%$ of total time) and were less active overall (16.88 vs. $18.50 \%$ of total time) than the high RFI group (Sadler et al., 2011). When selecting Large White swine for RFI, Barea et al. (2010) concluded that positive RFI pigs were energetically less efficient, in part because of greater physical activity.

Activity contributes a substantial proportion of the variation in RFI in poultry as well (Braastad and Katle, 1989; Katle, 1991; Luiting et al., 1991b). It has been reported that $80 \%$ of the genetic difference in RFI in divergent lines could be attributed to physical activity (Luiting et al., 1991b). Further evidence of this relationship has been reported in mice (Bunger et al., 1998; Mousel et al., 2001), in which lines selected for divergence in feed intake or heat loss (high vs. low) exhibited different levels of activity. In ruminants, the relationship between activity and RFI has not been studied thoroughly, although Richardson et al. (1999) reported that RFI was correlated positively with a pedometer count, and that activity accounted for around $10 \%$ of the variation in RFI (Richardson and Herd, 2004). 


\section{Digestibility}

It is estimated that differences in digestibility are responsible for approximately $10 \%$ of the observed variation in RFI in ruminants (Richardson and Herd, 2004); however, digestibility was not an important source of variation in RFI in monogastrics [poultry (Luiting et al., 1994), pigs (de Haer et al., 1993), and mice (Bunger et al., 1998)]. This relationship in ruminants may be associated with rate of passage, as it is known that passage rate increases and digestibility decreases as level of feed intake relative to maintenance increases; however, there is genetic variation in total tract digestion of feed over and above the systematic variation due to intake (Richardson and Herd, 2004).

In steers that were individually fed a concentrate-based diet under controlled environmental conditions, digestibility was correlated negatively $(r=-0.44)$ with RFI (Richardson et al., 2004), indicating that low RFI was associated with greater digestibility (Richardson and Herd, 2004). In this study, digestibility accounted for $19 \%$ of the variation in RFI; however, an earlier study by Richardson et al. (1996) reported that digestibility differed by only 1\% $(\mathrm{P}<0.10)$ between RFI classifications in Angus bulls and heifers, while digestibility accounted for $14 \%$ of the observed variation in intake. In hybrid steers, apparent DM digestibility was greatest in the low RFI group (75.33\%) and tended $(\mathrm{P}=0.10)$ to differ from high RFI steers $(70.87 \%)$, but was similar to the intermediate RFI group (73.40\%) (Nkrumah et al., 2006). Although it is likely that

digestibility contributes to variation in RFI, precise measurement of small differences in digestibility is difficult and conclusive evidence is not yet available. 


\section{Protein Turnover, Tissue Metabolism and Stress}

The general processes of metabolism are responsible for a large proportion of an animal's maintenance requirements. Thus it is logical to predict that a measure of feed utilization efficiency like RFI would be related to or influenced by measureable indicators of metabolic status. In fact, differences have been reported between RFI classes with respect to serum concentrations of glucose (Richardson et al., 2004 and Kolath et al., 2006a), insulin (Richardson et al., 2004 and Kelly et al., 2010b), nonesterified fatty acids (NEFA) (Kelly et al., 2010a), $\beta$-hydroxybutyrate (Richardson et al., 2004; Kelly et al., 2010a; Kelly et al., 2010b), and urea (Kelly et al., 2010b) in young growing cattle. In the previous reports, high RFI was associated with greater circulating concentrations of serum metabolites indicating a greater rate of catabolic activity in less efficient animals. Interestingly, when evaluating similar indicators of metabolism in gestating heifers, Lawrence et al. (2011) reported no differences among high, medium, or low RFI classes with respect to albumin, glucose, NEFA, triglycerides, or urea. High RFI heifers, however, tended $(\mathrm{P}=0.07)$ to have greater $\beta$-hydroxybutyrate concentrations while having significantly lower plasma creatinine (174.63 vs. 187.19 umol/L) than low RFI heifers, confirming that physiological state of production influences maintenance metabolism and may potentially impact RFI.

Castro Bulle et al. (2007) noted that maintenance energy requirements of crossbred steers increased $0.0166 \mathrm{Mcal} / \mathrm{BW}^{0.75} / \mathrm{day}$ for each one percent increase in fractional protein degradation rate, although no relationship existed between RFI and protein synthesis or degradation. Conversely, Richardson et al. (2004) reported that RFI was correlated positively with aspartate aminotransferase and both plasma urea and 
protein and negatively correlated with plasma creatinine $(r=-0.45)$. Further evidence that circulating aspartate aminotransferase and creatinine differ between RFI classes in cattle were reported by Lawrence et al. (2011), indicating a greater rate of protein turnover in high RFI animals. Similar results have been obtained in poultry (Bottje and Carstens, 2009). It has been hypothesized that the observed increase in protein turnover was due to the uncoupling of oxidative phosphorylation from electron transport, which results in the production of reactive oxygen species and increased protein oxidation. However, the observations of Kolath et al. (2006a) with respect to mitochondrial electron leakage in high and low RFI steers do not support this hypothesis. Still, Kolath et al. (2006a) reported that electron transfer was more efficient in low RFI steers due to a greater coupling of oxidative phosphorylation and respiration. Additional circumstantial evidence supporting the hypothesis of the inefficiency of electron transport can be found in the report by Richardson et al. (2002), who noted that high RFI cattle have larger red blood cells, more hemoglobin, and as a result, a greater oxygen carrying capacity and requirement. Logically, later authors evaluated mitochondrial uncoupling protein expression in differing RFI classes of cattle (Kolath et al., 2006b and Sherman et al., 2008) and swine (Lefaucheur et al., 2011) and observed no differences due to RFI classification. In contrast, Sharifabadi et al. (2012) reported that RFI was strongly related to mitochondrial respiratory chain complex activity ( $\mathrm{r} \leq-0.87$ for all five complexes; $\mathrm{P}<$ 0.001). Additionally, mitochondrial respiratory chain complex activity was significantly greater $(\mathrm{P}<0.001)$ for all five complexes in low compared to high RFI lambs, indicating that mitochondrial function, efficiency, and genetics may play major roles in determining efficiency phenotype; however, it still seems logical that observed differences in RFI are 
likely due, in part, to differences in protein turnover and potentially to differences in the efficiency of the liver to produce gluconeogenic substrates.

Although stress response is not often considered in evaluating animals for feed efficiency, physiological responses to stress include an increase in metabolic rate and energy consumption coupled with increases in catabolic processes such as increased lipolysis and protein degradation (Knott et al., 2008). As such, stress response or rather basal stress levels should be considered as potential sources of variation in feed efficiency of livestock, but have received only limited evaluation to date. Richardson et al. (2004) reported that plasma cortisol was positively associated $(r=0.40)$ with RFI in Angus steers, which is in agreement with reports in poultry (Luiting et al., 1994) and sheep (Knott et al., 2008). Conversely, Lefaucheur et al. (2011) reported that low RFI boars tended to have greater circulating concentrations of cortisol (64.9 vs. $51.2 \mathrm{ng} / \mathrm{mL}$; P $=0.08$ ) than high RFI groups after 4 generations of selection for RFI. Across species these results are inconclusive, but may mean that high RFI ruminants have greater basal concentrations of cortisol, a larger stress load and thus an increased metabolic rate. Previous reviews have indicated that the combination of stress, protein turnover, and tissue metabolism is responsible for 37\% of the variation in RFI (Richardson and Herd, 2004; Herd and Arthur, 2009). 


\section{INTEGRATION OF BIOLOGICAL MECHANISMS}

Our current knowledge of the complexity of the processes of metabolism and energy partitioning should be an indicator that no single mechanism is likely to be responsible for observed differences in feed efficiency phenotypes. In fact, this is true even for traits that are much simpler to measure (i.e. growth rate and wool production) than RFI (Oddy, 1999). As RFI is a moderately heritable trait, phenotypic RFI accounts for around $40 \%$ of the additive genetic variation in the trait; however, the diversity of the biological mechanisms described previously that impact RFI are likely influenced by non-additive genetic effects as well. Thus, it is expected that RFI is influenced not only by a variety of those mechanisms discussed above but also by their interactions. Even so, the majority of the variation in RFI that has been identified is based largely on circumstantial evidence and at least $27 \%$ of the variation in RFI remains unaccounted for (Herd and Arthur, 2009).

Summary of the available evidence indicates that low RFI (more efficient) animals are leaner, less active, and eat less but in a more defined pattern. Logically, this makes sense because it takes more energy to build adipose tissue and greater activity results in greater basal energy expenditure and thus the need for greater feed intake. Specifically in the case of ruminants, more efficient animals have reduced energy loss during fermentation and greater apparent GIT digestibility, indicating that genotype and/or genotype $\mathrm{x}$ environment interactions actually influence not only rumen and GIT physiology but also the development of a symbiotic relationship with more efficient microbial species. It is possible that passage rate differences may exist between RFI 
phenotypes, but this has not yet been investigated. Perhaps most important are the reported differences in RFI phenotypes at the cellular level. From these reports, it is apparent that there are marked differences in the rates of protein turnover and energy generation among RFI groups. Much of this evidence is reportedly associated with mitochondrial functions stemming from mitochondrial DNA, so it seems logical to assume that evaluating those factors responsible for sex differences in metabolism and efficiency may be important to improving our understanding of RFI. In effect, female livestock, who are responsible for the transfer of mitochondrial DNA, may have a much greater impact on the future of RFI research and selection than males. 


\section{STATEMENT OF PROBLEM AND OBJECTIVES}

Even though beef prices are an all-time high, input costs continue to rise, and beef producers must seek out ways in which to remain not only profitable but economically sustainable. In the beef industry, producers can increase income only by increasing unit production levels or expansion. With a large portion of the country experiencing extremes in weather and calf prices predicted to remain high through 2014, it is unlikely that expansion will serve as a means for producer's to increase economic return for the next several years. As well, increasing levels of production is associated with greater costs and is subject to the law of diminishing returns. Given that profit is equal to income minus costs, it seems logical that producers should consider reducing input costs while maintaining or selecting for optimum production.

Approximately $70 \%$ of the total cost of beef production is related directly to feed consumption (Herd et al., 1998; Liu et al., 2000). Around 70\% of feed costs are attributable to maintenance functions of mature females (Gregory, 1972; Ferrell and Jenkins, 1985; Montano-Bermudez et al., 1990). As such, logic dictates that identifying animals that consume less feed for equal or optimal production will serve to increase profitability and ensure economic stability. By comparing an animal's actual feed intake to a predicted intake based on its requirements for maintenance and performance, RFI provides beef producers with the means to do just that (Koch et al., 1963); however, RFI is a complex trait that requires the measurement of individual animal feed intake. As a result, researchers have only recently been able to investigate the potential of RFI as an economically important trait in selection programs. 
To date, most investigations involving RFI have focused on the possibility for indirect selection effects by evaluating the potential for phenotypic and genetic relationships with other economically important traits. However, few studies have evaluated those factors that are responsible for the variation observed in RFI-tested populations. Even though a number of factors have been identified (Figure 1), a large portion of the variation in RFI remains unaccounted for (Herd and Arthur, 2009). Thus, the primary objective of the present study was to evaluate several previously untested factors as potential sources of variation in RFI. Reports indicate that RFI is related to diet digestibility (Richardson et al., 2004; Nkrumah et al., 2006), fermentation products (Nkrumah et al., 2006), and feed intake (Arthur et al., 2001), so the primary objectives were to evaluate differences in nutrient absorption, digesta rate of passage, and rumen environment and fermentation products between RFI classes and across different diets and feeding levels. Additionally, the relationship between previously determined RFI and grazing forage intake was evaluated. 


\section{MATERIALS AND METHODS}

Studies were conducted over a 1.5 year period from September, 2009 to March, 2011 and included 5 separate experiments for which data will be presented. All studies were conducted at the West Virginia University Animal Science Farm in Morgantown, WV.

\section{Animals and Management}

The data were collected using 14 crossbred steer progeny of first parity, British breed type dams with known RFI phenotypes. Steers originated from the WVU Reedsville ( $\mathrm{n}=7)$ and the WVU Reymann Memorial Farm $(\mathrm{n}=7)$ Experiment Stations

and were sired by a commercially available Angus sire via artificial insemination. As a result, all steers were > 50\% Angus and were born in March and April of 2009 and subsequently weaned in early September of the same year. Details on the breeding procedures and determination of dam RFI have been described previously by Shaffer et al. (2011).

Due to varying procedures between farm units, calves from the WVU Reymann Memorial Farm remained intact males until after weaning. Approximately two weeks post weaning, calves were castrated by first using a bander (EZE Castrator Model T-1, Wadsworth Manufacturing, St. Ignatious, MT) and then removing the necrotic scrotal tissue with a scalpel approximately seven days later. Steers from the WVU Reedsville Farm were castrated at birth.

All procedures and facilities used in this study were approved by the West Virginia University Animal Care and Use Committee (IACUC \# 06-0104). 


\section{Data Collection and Test Procedures}

Experiment 1: Drylot-Forage-based Grower Diet (September 2009 - December 2009)

Steers were weaned approximately 30 day prior to start of the experiment and acclimated to the test diet (Table 1), which was designed to achieve moderate growth rates and allow for accurate comparison of feed efficiency rank (NRC, 1996). A 67-day feeding period was utilized in this experiment and steer BW was recorded weekly. Initial and final BW's were the average of BW measures collected on consecutive days. Individual feed intake data were collected using the GrowSafe 6000E System (GrowSafe Systems, Airdrie, Alberta, Canada) to be used in the calculation of RFI.

Steers were housed in a drylot facility (14.6 m x $9.1 \mathrm{~m}$ under roof) that contained 6 GrowSafe feeding nodes and were provided fresh feed once daily. The diet consisted of $40 \%$ corn silage, $40 \%$ ground second cutting grass hay, and $20 \%$ protein and energy supplement. Diet and supplement details can be found in Table 1.

On days 60,62, and 64, a blood sample was collected via jugular venipuncture at 0630 immediately prior to feeding. During this 5-day collection period, feed was delivered daily at a rate $11.34 \mathrm{~kg}$ of fresh feed/head/day, equivalent to $2.5 \%$ of $\mathrm{BW}$ in DM, and was verified to be consumed entirely within 2 hours by visual observation. In order to achieve consistent consumption, feed was placed in concrete $\mathrm{J}$ bunks adjacent to the GrowSafe feeding nodes so that $0.61 \mathrm{~m}$ of bunk space was allocated for each steer. Additional blood samples were collected every 3 hours for the next 12 hours. Samples were refrigerated overnight, at which time plasma was harvested, split into two samples for individual assay, and stored at $-20^{\circ} \mathrm{C}$ until blood metabolites (volatile fatty acids 
(VFA's), glucose, cholesterol, triglycerides, albumin, and urea nitrogen) were quantified.

An illustration of the collection procedures and time points can be found in Figure 2.

Table 1. Composition and nutrient analysis of diet for Experiment 1

\begin{tabular}{lc}
\hline \hline Ingredients & As Fed \% \\
\hline Corn Silage & 40.6 \\
Grass Hay $^{1}$ & 40.5 \\
Supplement $^{2}$ & 18.9 \\
\hline Nutrient Analysis $^{2}$ DM \% \\
\hline Dry Matter & 68.21 \\
Ash & 8.18 \\
Crude Protein & 10.03 \\
NDF & 63.03 \\
ADF & 26.13 \\
Soluble Protein & 23.18
\end{tabular}

${ }^{1}$ Grass hay was ground to a 2.5 to $5 \mathrm{~cm}$ particle length.

${ }^{2}$ Supplement was composed of $52.24 \%$ soyhulls, $21.11 \%$ ground corn, $15.83 \%$ soybean meal, $8.44 \%$ mineral premix ${ }^{3}$, and $2.37 \%$ salt.

${ }^{3}$ Southern States 4:1 Beef Mineral, Southern States Cooperative, Richmond, VA.

After collection of the last blood sample at $1900 \mathrm{~h}$, approximately $100 \mathrm{ml}$ of rumen fluid were collected from each steer via an oral lavage using an apparatus similar to that described by Lodge-Ivey et al. (2009) inserted through a Frick speculum. Rumen fluid samples were immediately strained through 3 layers of cheesecloth and rumen $\mathrm{pH}$ was determined using a pH meter (ThermoORION model 310 perpHecT logRmeter, Thermo Fisher Scientific, Waltham, MA) by allowing the probe to rest in approx. 100 $\mathrm{mL}$ of rumen fluid for around $10 \mathrm{sec}$. Immediately prior to and after recording rumen fluid $\mathrm{pH}$, the probe of the $\mathrm{pH}$ meter was rinsed with distilled water. When not in use, the 


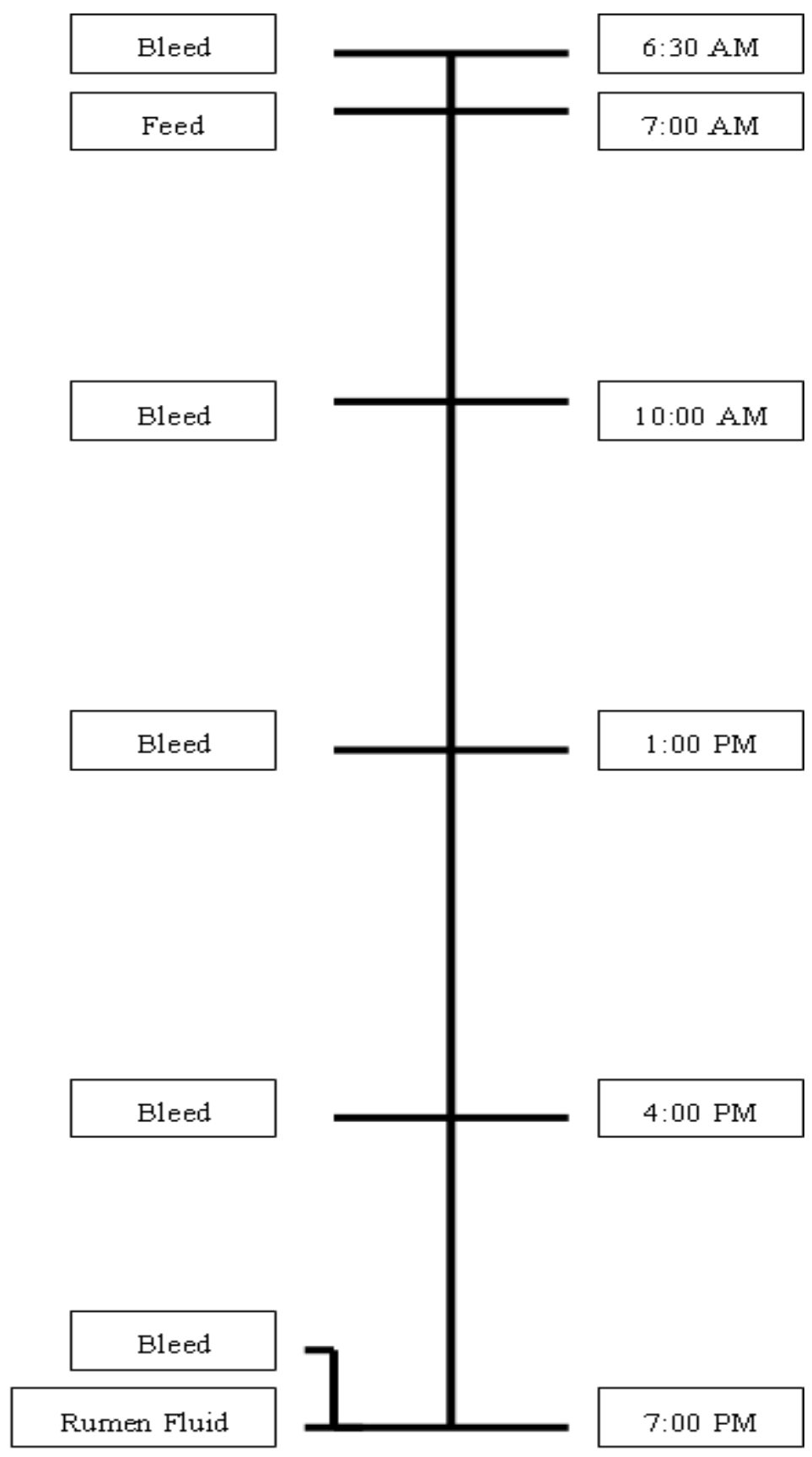

Figure 2. Schematic of experimental procedures. 
probe was stored in a bath of pH 7 buffer solution (SB107-500, Thermo Fisher Scientific, Waltham, MA). Additionally, $50 \mathrm{~mL}$ of rumen fluid was pipetted into a $50 \mathrm{~mL}$ conical bottom centrifuge tube and acidified by the addition of $1 \mathrm{ml}$ of $0.5 \mathrm{~N} \mathrm{HCl}$ and frozen until further analyzed for ammonia concentration. Similarly, $2 \mathrm{ml}$ of strained rumen fluid were pipetted into a separate $50 \mathrm{ml}$ conical bottom centrifuge tube and immediately returned to the lab where VFA's were extracted.

Experiment 2: Summer Pasture Intake Determination (September 2010)

Prior to Experiment 2, steers were developed as contemporaries post-weaning as described in Experiment 1. Between Experiments 1 and 2, steers were fed a diet consisting of cool season grass hay. Prior to the start of Experiment 2 but after hay feeding, steers were grazed on cool season grass pastures for approximately 120 days (May to August, 2010) and individual steer body weight was recorded monthly to determine grazing ADG. For Experiment 2, steers were stratified by body weight and previous gain performance on forage and allotted to one of three grazing plots where individual forage intake data were collected.

Grazing paddocks $(\mathrm{n}=3)$ were approximately one hectare in size and each paddock was divided into 8 approximately equally sized subplots to be grazed rotationally. Each subplot was grazed one day with each paddock containing one group (two groups of 5 and one group of 4) of steers. Forage samples and sward height data were collected from each subplot immediately pre- and post-grazing. Sward height measurements were collected using a falling plate meter (Rayburn and Lozier, 2003) following similar transects of the grazing plots pre and post-grazing. Approximately 2025 height measurements were collected from each subplot by taking a measurement at 2 
$\mathrm{m}$ intervals along two transects perpendicular to the shortest side of each triangular shaped subplot and one transect perpendicular to the first two at the midpoint of the plot. A schematic of the forage plots is presented in Figure 3. Forage samples were collected from three random points along the height measurement transects in each subplot by hand clipping the forage to a height of approximately $3 \mathrm{~cm}$. Forage samples were dried in a forced air oven at $55^{\circ} \mathrm{C}$ for $48 \mathrm{~h}$, and ground through a $1 \mathrm{~mm}$ screen using a Wiley mill. Samples were then analyzed for ADF, NDF, total CP and DM (Table 2). Grazed forages were predominately mixed cool season grasses and legumes consisting of Kentucky bluegrass (Poa pratensis L.), orchardgrass (Dactylis glomerata L.), tall fescue (Festuca arundinacea L.), red clover (trifolium pretense L.), and white clover (Trifolium repens L.).

Approximately 1 month prior to initiation of the experiment, steers were allocated to grazing groups and placed in subplot 1 of each respective grazing paddock. Steers were allowed to graze the subplot for 1 day and then rotated in sequence through all 8 subplots, grazing each for a period of 1 day. Standing forage was removed in experimental sequence such that time of regrowth and forage quality variation would be equalized for each sublot during the experimental period. Sward height estimates of subplot forage mass were used to determine when forage availability would not be limiting to voluntary forage intake. Due to dry conditions, sufficient forage regrowth was not available until approximately 6 weeks after subplot preparation. Estimated available forage mass was 22.7, 26.4, and $22.2 \mathrm{~kg} \mathrm{DM/head/day} \mathrm{for} \mathrm{grazing} \mathrm{plots} \mathrm{1,} \mathrm{2,} \mathrm{and} \mathrm{3,}$ respectively, based upon the falling plate meter calibration factor of $77 \mathrm{~kg}$ of DM per centimeter of height for cool season mixed grass pastures (Rayburn and Lozier, 2003). 
After grazing, remaining forage mass was estimated to be 17.3, 20.5, and 16.4

$\mathrm{DM} /$ head/day for plots 1,2 , and 3, respectively, indicating that forage mass was not limiting to intake.

During the grazing period preceding intake measurement (May to August, 2010), forage growth rate exceeded grazing consumption and forages matured. Mature forage was removed mid-summer by mechanically clipping paddocks to a height of approximately 15 - $20 \mathrm{~cm}$ using a tractor and brush hog. The remaining forage was removed by grazing. As a result, forage consumed during the intake measurement and plot preparation periods was vegetative regrowth.

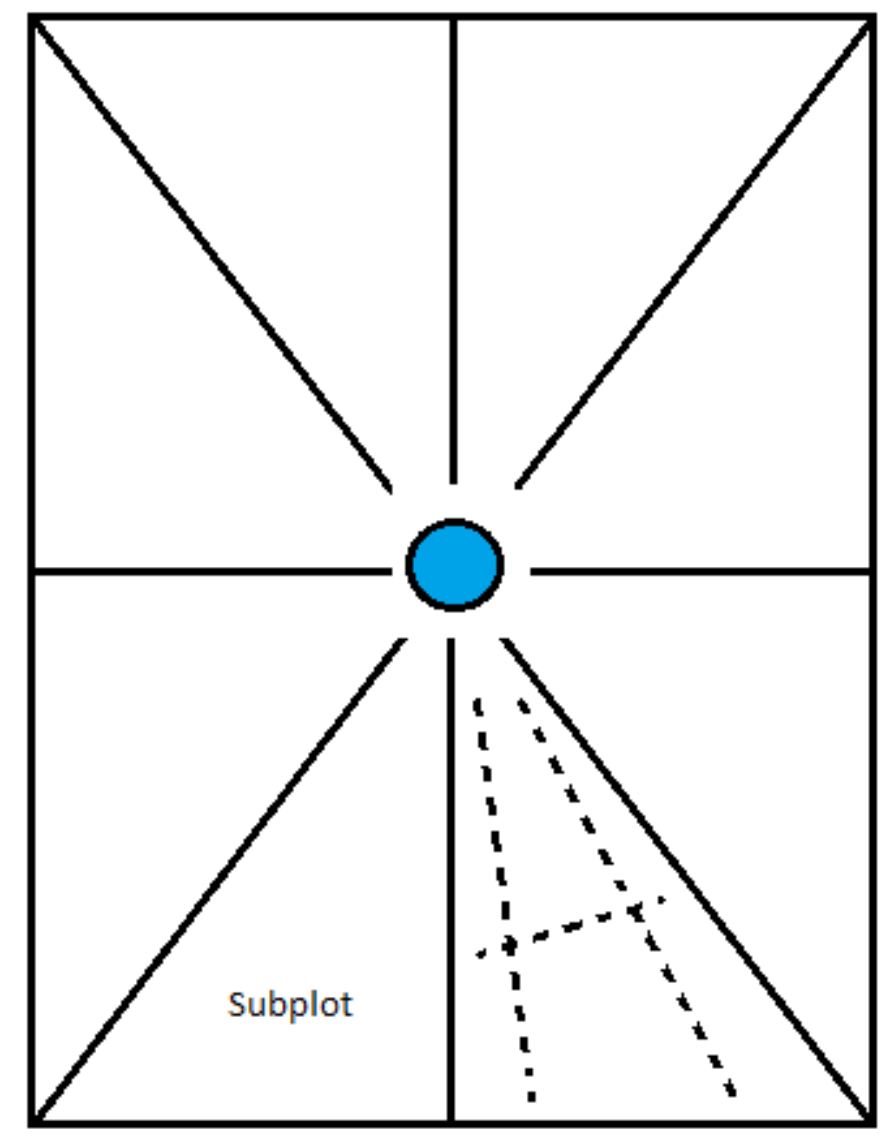

Figure 3. Schematic representation of the grazing plots used in determination of grazing forage intake. Each triangular shaped portion represents a subplot, or the grazing allotment for one day. Sward height measurements were taken following transects represented by the dashed lines. 
Table 2. Nutrient analysis of grazed forage for Experiments 2 and 3.

\begin{tabular}{lc}
\hline \hline Nutrient Analysis & $\% \mathrm{DM}$ \\
\hline Dry Matter & 36.51 \\
Ash & 8.70 \\
Crude Protein & 13.43 \\
NDF & 62.34 \\
ADF & 30.33 \\
Soluble Protein & 71.09 \\
\hline
\end{tabular}

On day 0 of the experiment all groups were placed in subplot 1 of their respective grazing paddock. Steers were allowed to graze ad libitum and had constant access to water and trace mineralized salt. Steers were removed from the plots twice daily for marker dosing and fecal collection. On days 1 to 7, steers were dosed orally at $0800 \mathrm{~h}$ and at 2000 h with a gelatin capsule (Size 10, Torpac, Inc., Fairfield, NJ) containing 10 g chromic oxide $\left(\mathrm{CrO}_{3}: 67 \% \mathrm{Cr}\right)$. Fecal grab samples were collected twice daily at 0800 and 2000 h from each steer on days 5 through 8 . Fecal samples were collected in sealed plastic containers and stored under refrigeration until dried. Samples were dried at $55^{\circ} \mathrm{C}$ in a forced air oven and then ground through a $2 \mathrm{~mm}$ screen using a Wiley mill. Chromium was then extracted from dried feces using sodium hypochlorite (chlorine bleach) and $1 \mathrm{M} \mathrm{HCl}$ according to the procedures of Suzuki and Early (1991). Fecal samples were then analyzed for chromium concentration using inductively coupled plasma mass spectroscopy (ICP-MS) (Dionex ICS-3000, ThermoScientific, Sunnyvale, CA). 
Voluntary forage dry matter intake on pasture was estimated by the equation DMI $=\mathrm{FO} /[1-($ diet digestibility/100) $]$ where FO $=$ fecal output. Fecal output $(\mathrm{kg} /$ day $)$ was estimated based on the ratio of the marker (Cr) dosed to the animal (mg) to its concentration in the feces (mg/g). Apparent dry matter digestibility was calculated as the percentage of forage dry matter found in feces $(\mathrm{kg} / \mathrm{d})$ less 100 . Forage dry matter (g/d) was calculated by first multiplying FO by the observed percentage of ash in feces less that of the marker to estimate fecal output of ash per day. This value was then divided by the observed percentage of ash in the pre-grazed forage samples to estimate forage DM (g/d). Pre-grazed forage ash values were the average of the 8 subplots within each grazing paddock and were used with the steers that grazed only that particular paddock. Experiment 3: Fall Pasture-Passage Rate (October 2010)

Prior to the beginning of the trial, steers were comingled and allowed to graze fall regrowth on cool season grass pastures equivalent to that described in Experiment 2 for approximately 1 month. Fecal grab samples were collected at random time points for each steer during this time. Undigested fecal fiber was collected from these samples by rinsing the wet feces (approximately $2 \mathrm{~kg} /$ steer) over a $3 \mathrm{~mm}$ sieve under flowing water. Undigested fecal fiber samples were then dried at $50^{\circ} \mathrm{C}$ in a forced air oven. Dried fecal fiber samples were then labeled with ytterbium chloride using the methods of Varga and Prigge (1982) and used as a solid phase marker in the determination of solids passage rate. Liquid phase passage rate was determined using Co-EDTA prepared by the methods of Uden et al. (1980).

At $1800 \mathrm{~h}$ on day 0 of the trial, each steer received a single oral dose of cobaltEDTA crystals (25 g) contained in a gelatin capsule and $50 \mathrm{~g}$ of ytterbium chloride 
labeled fecal fiber, which was thoroughly mixed with approximately $1 \mathrm{~kg}$ of soybean hull pellets and fed to the steers in individual feeding stalls. Each steer consumed the ytterbium chloride labeled fecal fiber recovered from their respective fecal grab samples. Immediately following dosing, steers were placed in a one hectare paddock and allowed to graze freely for the remainder of the trial except when removed for fecal collection. Steers were removed from the paddock twice daily at 12-hour intervals from dosing for collection of fecal grab samples. A total of 8 fecal grab samples were collected per steer post-dosing over a 4-day period. Samples were collected in sealed plastic containers and stored under refrigeration until dried. Samples were dried at $55^{\circ} \mathrm{C}$ in a forced air oven and then ground through a $2 \mathrm{~mm}$ screen using a Wiley mill. Ytterbium and cobalt were extracted simultaneously from dried feces using diethylenetiraminepentaacetic acid (DTPA) according to the procedures of Karimi et al. (1987). Ytterbium and cobalt concentrations in feces were then determined by ICP-MS (Dionex ICS-3000, ThermoScientific, Sunnyvale, CA) and used in the calculation of solid and liquid phase passage rate, respectively.

Experiment 4: Maintenance Feeding—Forage (February 2011)

Prior to the start of the experimental period, steers were placed in a drylot facility and given access to three pens each measuring $4.9 \mathrm{~m}$ x $9.1 \mathrm{~m}$ with an area of $4.9 \mathrm{~m} \times 4.9$ m under roof. Concrete feed bunks fitted with wooden dividers lined the front of the pens. Individual stanchions constructed of $5.1 \mathrm{~cm}$ steel pipe and backed by a steel gate were placed in front of the bunks to facilitate individual feeding. Approximately $0.61 \mathrm{~m}$ of bunk space was allocated to each steer. 
The experiment consisted of a 10-day adaptation period and a 5-day collection period and steer BW was collected daily. Steers were limit fed at maintenance (1.5\% BW as fed) a ration containing ground first cutting, cool season grass hay and $0.1 \mathrm{~kg}$ per day soybean meal to assure adequate rumen nitrogen levels. Nutrient content of dietary ingredients can be found in Table 3. Feed was delivered at $0700 \mathrm{~h}$ daily and steers were confined to the stanchions until feed was consumed (approx. $2 \mathrm{~h}$ ). Steers had access to fresh water and mineral supplement at all other times.

On days 11, 13, and 15, a blood sample was collected via jugular venipuncture at 0630 immediately prior to feeding. Additional samples were collected beginning 3 hours post-feeding and subsequently at 3-hour intervals until a total of 5 samples were collected or 12 hours post-feeding. Samples were collected in 10-mL evacuated blood collection tubes containing $0.10 \mathrm{~mL}$ of 15\% EDTA solution (Tyco Healthcare Group, Mansfield, MA). Samples were refrigerated overnight at $4^{\circ} \mathrm{C}$, after which plasma was harvested by centrifugation $\left(3,000 \times \mathrm{g}\right.$ at $4^{\circ} \mathrm{C}$ for $\left.20 \mathrm{~min}\right)$, split into two samples for individual assay, and stored at $-20^{\circ} \mathrm{C}$.

After collection of the last blood sample at $1900 \mathrm{~h}$, approximately $100 \mathrm{ml}$ of rumen fluid were collected from each steer and processed for rumen $\mathrm{pH}$, ammonia, and ruminal VFA's as described in Experiment 1.

Experiment 5: Maintenance Feeding—Concentrate (March 2011)

Experiment 5 was performed as an exact replicate to Experiment 4 only using a concentrate-based diet. In this experiment, the diet consisted of $10 \%$ ground first cutting grass hay with the remainder of the diet balanced on an individual animal basis using ground corn and soybean meal to deliver equal CP and TDN (New York State TDN 
Equation-Complete Feed; National Forage Testing Association, 1993) as the diet in Experiment 4.

Table 3. Nutrient analysis of dietary components for Experiments 4 and 5

\begin{tabular}{lccc}
\hline \multirow{2}{*}{ Nutrient Analysis } & \multicolumn{3}{c}{ Ingredients $^{12}$} \\
\cline { 2 - 3 } & Ground Corn & Soybean Meal & Grass Hay ${ }^{3}$ \\
\hline Dry Matter & 89.09 & 89.46 & 93.71 \\
Ash & 1.28 & 6.02 & 5.11 \\
Crude Protein & 7.96 & 45.93 & 7.38 \\
NDF & 17.12 & 14.53 & 68.57 \\
ADF & 1.98 & 5.19 & 40.33 \\
Soluble Protein & 64.88 & 67.50 & 69.54 \\
${ }^{1}$ Values expressed as \% DM. & \\
${ }^{2}$ Trace mineral salt was provided free choice through Experiments 4 and 5.
\end{tabular}

\section{Plasma Samples: Experiments 1, 4, and 5}

Determination of Plasma Metabolite Concentration

Concentrations of albumin (ALB), cholesterol (CHO), glucose (GLU), triglycerides (TG), and urea nitrogen (UN) were quantified by absorbance on a spectrophotometer (Molecular Devices SPECTRAmax PLUS 384, Sunnyvale, CA) using commercially available colorimetric assay kits (Stanbio LiquiColor, Kit \#’s 0285, 1010, 1070, and 2100 for ALB, CHO, GLU, and TRI, respectively, and Stanbio Enzymatic Urea Nitrogen, Kit \#2050, Stanbio Laboratories, Boerne, TX) adapted to flat bottom 96 well plates and previously used with bovine plasma (Lee et al., 2009). Plates were run in duplicate for each variable and contained samples from an entire collection day $(n=70 ; 5$ 
samples per steer x 14 steers). Mean inter and intra-assay CV’s were 9.86 and 9.37\%, respectively, and the sensitivity for minimum detection was $0.066 \mathrm{mg} / \mathrm{dL}$ for UN with the remaining assays being linear from zero.

Plasma Volatile Fatty Acid Determination

Volatile fatty acids were extracted from plasma (200 $\mu \mathrm{L})$ in duplicate using $1 \mathrm{~mL}$ of $100 \%$ ethanol in $1.5 \mathrm{~mL}$ snap top microcentrifuge tubes (Thermo Fisher Scientific, Waltham, MA). After vortexing, samples were centrifuged at 12,000 rpm for 15 min and $800 \mu \mathrm{L}$ of supernatant was transferred into similar microcentrifuge tubes containing $20 \mu \mathrm{L}$ 0.2 M sodium hydroxide and vortexed. Supernatant was then evaporated to dryness under an air current at $30^{\circ} \mathrm{C}$. The dry residue was reconstituted in $20 \mu 1$ of 30 $\mathrm{mM}$ oxalic acid and $1 \mu \mathrm{l}$ of the reconstituted sample was injected onto a $2 \mathrm{~m}$ x 2 mm I.D. glass column (80/120 Carbopack B-DA/4\% Carbowax 20M, Supelco Inc., Bellefonte, PA) within a gas chromatograph (Varian 3300, Varian Inc, Walnut Creek, CA;

Integrator: Varian 4290, Varian Inc, Walnut Creek, CA) to quantify plasma volatile fatty acid (PVFA) concentrations (Remesy and Demigne, 1974).

\section{Rumen Samples: Experiments 1, 4, and 5}

Rumen Fluid Ammonia Determination

Frozen acidified rumen fluid samples were thawed to room temperature, vortexed, and $10 \mathrm{~g}$ (sample weight) weighed into duplicate Kjeldahl tubes. Greater than $2.0 \mathrm{~g}$ of magnesium oxide was added to each tube and dissolved by mixing. The $\mathrm{pH}$ of the rumen fluid magnesium oxide solution was verified as basic using litmus paper. Nitrogen content of the solution was then analyzed using a Tecator Kjeltec Auto 1030 Analyzer 
(FOSS in North America, Eden Prarie, MN). Sample $\mathrm{NH}_{4}$ concentration (mg/dL) was calculated as [(a x b 14.01/(c)] x 100 where:

$$
\begin{aligned}
& \mathrm{a}=\mathrm{mL} \text { of titrant acid used } \\
& \mathrm{b}=\text { Normality of acid (0.02) } \\
& \mathrm{c}=\text { sample weight }
\end{aligned}
$$

\section{Rumen Fluid Volatile Fatty Acid Determination}

Five $\mathrm{ml}$ of fresh strained rumen fluid were pipetted into $50 \mathrm{ml}$ nalgene conical bottom centrifuge tubes containing $5 \mathrm{ml}$ of an internal standard solution consisting of $75.17 \mu \mathrm{mol} / \mathrm{mL}$ acetic acid, $20.09 \mu \mathrm{mol} / \mathrm{mL}$ propionic acid, $18.15 \mu \mathrm{mol} / \mathrm{mL}$ butyric acid, $5.01 \mu \mathrm{mol} / \mathrm{mL}$ isobutyric acid, $4.97 \mu \mathrm{mol} / \mathrm{mL}$ valeric acid and $5.25 \mu \mathrm{mol} / \mathrm{mL}$ isovaleric acid. After standing for 30 minutes at room temperature, tubes were centrifuged at 12,000 rpm for $15 \mathrm{~min}$. Supernatant was then recovered into $1.5 \mathrm{ml}$ snap top microcentrifuge tubes labeled in duplicate and stored under refrigeration. Rumen VFA's concentrations were then analyzed via gas-liquid chromatography (Varian 3300 Gas Chromatograph, Varian Inc, Walnut Creek, CA; Integrator: Varian 4290, Varian Inc, Walnut Creek, CA) by injecting $1 \mu$ of the sample onto a $2 \mathrm{~m}$ x $2 \mathrm{~mm}$ I.D. glass column (80/120 Carbopack B-DA/4\% Carbowax 20M, Supelco Inc., Bellefonte, PA) maintained at $175^{\circ} \mathrm{C}$ and using nitrogen as a carrier gas. Nitrogen flow rate was $24 \mathrm{cc} /$ minute and both the injector and detector were maintained at $200^{\circ} \mathrm{C}$.

\section{Determination of RFI}

Individual feed intake data were collected for 67-days in Experiment 1; however, the data were lost due to computer failure and the calculation of individual RFI was not possible. Luckily, maternal RFI had been determined in a previous post-weaning test 
(Shaffer et al., 2011). Knowing that paternal genetic variation in efficiency was minimized by all steers being progeny of a single sire, previously determined dam RFI should adequately represent individual RFI phenotype. Therefore, dam RFI value was treated as individual RFI for purposes of treatment classification and analysis.

\section{Statistical Analyses}

The data were analyzed with steer as the experimental unit, with steers classified into groups based upon dam RFI rank. Differences in rumen $\mathrm{pH}(\mathbf{P H})$, rumen ammonia (NH4), and rumen volatile fatty acids (RVFA), more specifically acetic (ACE), propionic (PRO), butyric (BUT), isobutyric (IBT), valeric (VAL), isovaleric (IVAL), total (TVFA), and acetate:propionate ratio (A:P) among steers classified as either high (HIGH; n = 8) or low (LOW; n =6) RFI based upon dam RFI were analyzed using the general linear model (GLM) of SAS (SAS Instituate; Cary, NC, 2006). The objective of the experiment was to determine the relationships of these values with RFI and differences between day of collection were anticipated, therefore collection day and collection time relative to feeding were used as covariates in the model.

Passage rate data were expressed as the detected concentration of the indigestible marker per gram of fecal DM. Marker concentrations were then linearized via a natural log transformation and regressed upon collection time post-dosing using the PROC REG procedure of SAS (2006). This resulted in a simple linear equation for each steer with an intercept and coefficient for the variable of collection time post-dosing, which is equivalent to the rate of appearance of the indigestible marker in the collected, dried feces. This coefficient was used to analyze RFI group differences for liquid (LPR) and solid passage rate (SPR) via the GLM procedure of SAS (2006). The statistical model 
contained only the fixed effect of RFI group and was used to evaluate differences among RFI classifications for voluntary DMI, ultrasonographic measures of body composition, and descriptive traits.

Concentrations of plasma VFA's and metabolites were treated as a response to feeding and were analyzed by the GLM procedure of SAS (2006). The model used to analyze overall mean concentrations and mean concentration post-feeding included collection day and collection time as covariates and RFI group as a fixed effect. In order to evaluate differences between RFI groups at each collection time, the interaction of RFI group and collection time was included in the model as a fixed effect and means were calculated for each combination of the RFI x Collection Time interaction. Phenotypic relationships between RFI and all measured traits were examined using the PROC CORR procedure of SAS (2006). Significance was determined for all analyses at $\mathrm{P}<0.05$. 


\section{RESULTS}

\section{General}

Descriptive statistics of steers prior to the start of Experiment 1 are presented in Table 4. Steers weighed an average of $38.4 \mathrm{~kg}$ at birth and were weaned at approximately 187 days of age. Mean 205-day adjusted weaning weight (WW) was 262.6 kg. Steers were classified as either positive (POS; $n=8)$ or negative $(\mathbf{N E G} ; n=6)$ based on dam phenotypic RFI (DRFI) value and further analyses served as a comparison of these differing RFI phenotypes. With the exception of DRFI, no differences were observed among RFI classes in pre- and post-weaning production traits (Table 5).

Table 4. Descriptive statistics of steers entering Experiment 1.

\begin{tabular}{lrccc}
\hline \hline Trait $^{1}$ & Mean & SD $^{2}$ & Minimum & Maximum \\
\hline Dam RFI (kg TDN/d) & 0.46 & 3.28 & -4.94 & 5.70 \\
Birth Weight (kg) & 38.36 & 3.05 & 33.57 & 43.55 \\
Weaning Weight (kg) & 262.57 & 25.28 & 222.41 & 301.44 \\
Weaning Age (days) & 186.86 & 13.55 & 158 & 204 \\
\hline
\end{tabular}

${ }^{1} \mathrm{RFI}=$ Residual feed intake; $\mathrm{TDN}=$ total digestible nutrients

${ }^{2} \mathrm{SD}=$ Standard deviation. 
Table 5. Descriptive statistics of steers classified as POSITIVE or NEGATIVE RFI.

\begin{tabular}{|c|c|c|c|c|}
\hline Trait $^{1}$ & $\mathrm{POS}^{2}$ & $\mathrm{NEG}^{2}$ & SEM $^{3}$ & $P$-value \\
\hline $\mathrm{N}$ & 8 & 6 & -- & -- \\
\hline Age (days) & 234.75 & 230.33 & 5.73 & 0.57 \\
\hline Birth Weight (kg) & 38.39 & 38.33 & 1.30 & 0.97 \\
\hline Weaning Weight (kg) & 272.50 & 249.34 & 9.48 & 0.09 \\
\hline On Test BW ${ }^{4}(\mathrm{~kg})$ & 267.54 & 236.74 & 15.22 & 0.15 \\
\hline Off Test BW ${ }^{4}(\mathrm{~kg})$ & 329.99 & 293.89 & 17.64 & 0.15 \\
\hline ADG (kg) & 0.98 & 0.89 & 0.05 & 0.27 \\
\hline \multicolumn{5}{|c|}{$\begin{array}{l}{ }^{1} \mathrm{RFI}=\text { Residual feed intake; } \mathrm{TDN}=\text { total digestible nutrients; } \mathrm{BW}=\text { Body weight; } \mathrm{ADG} \\
=\text { average daily gain. }\end{array}$} \\
\hline \multicolumn{5}{|c|}{$\begin{array}{l}\text { 2 Mean dam RFI values for steers classified as POSITIVE or NEGATIVE were } 2.78 \text { and } \\
\text {-2.64, respectively. }\end{array}$} \\
\hline \multicolumn{5}{|c|}{${ }^{3}$ Pooled standard error of treatment means. } \\
\hline
\end{tabular}

\section{Experiment 1: Drylot-Forage-based Grower Diet}

In general, production traits and measured variables did not differ between RFI groups for Experiment 1. Steer gain performance, initial BW, or final BW did not differ between RFI groups (Table 5). No differences were observed in ultrasonographic measures of body composition at the initiation of Experiment 1 (Table 6); however, RUF was greater in POS steers when compared to NEG steers at trial conclusion (42.23 vs. 29.63 mm, respectively; $\mathrm{P}=0.02$ ). No other final measures of body composition differed based upon RFI class.

Rumen $\mathrm{pH}, \mathrm{NH}_{4}$, and VFA data were similar for RFI groups (Table 7). Similarly, overall concentrations of ALB, UN, GLU, and TG were similar between RFI classes 
Table 6. Ultrasonic measures of body composition among POSTIVE and NEGATIVE RFI steers.

\begin{tabular}{|c|c|c|c|c|c|c|c|c|}
\hline \multirow[b]{2}{*}{ Trait $^{1}$} & \multicolumn{2}{|c|}{ Initial } & \multirow[b]{2}{*}{$\mathrm{SEM}^{2}$} & \multirow[b]{2}{*}{$P$-value } & \multicolumn{2}{|c|}{ Final } & \multirow[b]{2}{*}{ SEM $^{2}$} & \multirow[b]{2}{*}{$P$-value } \\
\hline & POS & NEG & & & POS & NEG & & \\
\hline RIF (mm) & 23.18 & 21.17 & 1.85 & 0.43 & 40.32 & 32.17 & 3.14 & 0.07 \\
\hline RUF (mm) & 20.96 & 22.01 & 1.96 & 0.69 & 42.23 & 29.63 & 3.56 & 0.02 \\
\hline $\operatorname{REA}\left(\mathrm{cm}^{2}\right)$ & 41.13 & 38.07 & 3.04 & 0.46 & 48.95 & 45.06 & 3.19 & 0.37 \\
\hline IMF (\%) & 4.37 & 4.09 & 0.38 & 0.60 & 4.92 & 4.75 & 0.42 & 0.76 \\
\hline REA/CWT $\left(\mathrm{cm}^{2} / 100 \mathrm{~kg}\right)$ & 15.31 & 16.15 & 0.67 & 0.36 & 14.85 & 15.31 & 0.56 & 0.55 \\
\hline
\end{tabular}

${ }^{1} \mathrm{RIF}=$ ultrasonographic $12^{\text {th }}$ rib back fat; RUF = ultrasonographic rump fat; REA = ultrasonographic $12^{\text {th }}$ rib ribeye area; IMF

= intramuscular fat; REAC/CWT = ribeye area per $100 \mathrm{~kg}$ body weight.

${ }^{2}$ Pooled standard error of treatment means. 
Table 7. Rumen $\mathrm{pH}$, ammonia, and volatile fatty acid concentrations among POSITIVE and NEGATIVE RFI steers for Experiment 1.

\begin{tabular}{lcccc}
\hline \hline Trait $^{1}$ & POS & NEG & SEM $^{2}$ & P-value \\
\hline Rumen pH & 7.30 & 7.37 & 0.07 & 0.42 \\
Rumen ammonia (mg/dL) & 0.87 & 0.79 & 0.10 & 0.54 \\
Acetic acid (mM/L) & 44.03 & 43.83 & 2.96 & 0.96 \\
Propionic acid (mM/L) & 10.30 & 9.84 & 0.77 & 0.66 \\
Butyric acid (mM/L) & 6.27 & 6.24 & 0.42 & 0.95 \\
Isobutyric acid (mM/L) & 0.45 & 0.45 & 0.03 & 0.85 \\
Valeric acid (mM/L) & 0.40 & 0.38 & 0.04 & 0.57 \\
Isovaleric acid (mM/L) & 0.28 & 0.28 & 0.03 & 0.86 \\
Total VFA (mM/L) & 61.74 & 61.02 & 4.18 & 0.87 \\
Acetate:Propionate & 4.39 & 4.51 & 0.09 & 0.33 \\
\hline
\end{tabular}

${ }^{1} \mathrm{VFA}=$ volatile fatty acid

${ }^{2}$ Pooled standard error of treatment means.

(Table 8). Cholesterol and branched VFA's concentrations tended ( $\mathrm{P}=0.09$ and 0.06 , respectively) to be greater in plasma of NEG RFI steers which also contained significantly greater $(\mathrm{P}=0.02$ ) concentrations of valeric acid (Table 8). Differences did exist in RFI classes over time for TG and isobutyric acid (Figure 4A and 4B, respectively). Triglyceride concentrations did not differ prior to feeding but were greater in NEG steers 3-hours post-feeding $(\mathrm{P}=0.04)$. In contrast, there was a tendency $(\mathrm{P}=$ 0.08) for POS steers to have greater TRI concentrations at 9-hours post-feeding. Residual feed intake classes did not differ at any other time points.

In general, plasma isobutyric acid concentrations were quite variable and did not differ from zero; however, isobutyric acid concentration was greater in NEG steers at 12- 
hours post-feeding $(\mathrm{P}<0.01)$. Conversely, POS steers tended $(\mathrm{P}=0.05)$ to have greater isobutyric acid concentrations at 3-hours post-feeding. Again, no differences were observed between RFI classes prior to feeding or at 6 and 9 hours post-feeding. As well, mean concentrations of plasma variables post-feeding did not differ between RFI classes (data not shown).

Table 8. Overall plasma metabolite and VFA concentrations in POSITIVE and NEGATIVE RFI steers for Experiment 1.

\begin{tabular}{|c|c|c|c|c|c|}
\hline Trait $^{1}$ & POS & NEG & $\mathrm{SEM}^{2}$ & $P$-value & RFI x Time ${ }^{3}$ \\
\hline ALB (g/dL) & 4.68 & 4.55 & 0.08 & 0.25 & 0.26 \\
\hline UN (mg/dL) & 11.14 & 10.48 & 0.61 & 0.41 & 0.85 \\
\hline CHOL (mg/dL) & 79.84 & 87.26 & 3.33 & 0.09 & 0.60 \\
\hline GLU (mg/dL) & 85.97 & 85.33 & 1.20 & 0.69 & 0.71 \\
\hline TG (mg/dL) & 7.90 & 8.36 & 0.54 & 0.52 & 0.04 \\
\hline Acetic acid (mM/L) & 1.684 & 1.521 & 0.08 & 0.13 & 0.12 \\
\hline Propionic acid (mM/L) & 0.024 & 0.022 & 0.001 & 0.31 & 0.57 \\
\hline Butyric acid (mM/L) & 0.013 & 0.010 & 0.002 & 0.34 & 0.51 \\
\hline Isobutyric acid (mM/L) & 0.005 & 0.005 & 0.003 & 0.88 & 0.02 \\
\hline Valeric acid (mM/L) & 0.142 & 0.232 & 0.027 & 0.02 & 0.23 \\
\hline Isovaleric acid (mM/L) & 0.011 & 0.011 & 0.001 & 0.96 & 0.75 \\
\hline Total VFA’s (mM/L) & 1.91 & 1.84 & 0.088 & 0.60 & 0.18 \\
\hline Acetate:Propionate & 85.29 & 86.37 & 8.19 & 0.92 & 0.98 \\
\hline Branched VFA's (mM/L) & 0.17 & 0.26 & 0.029 & 0.06 & 0.15 \\
\hline
\end{tabular}

${ }^{1} \mathrm{ALB}=$ albumin; UN = urea nitrogen; $\mathrm{CHOL}=$ cholesterol; GLU = glucose; $\mathrm{TG}=$ triglycerides.

${ }^{2}$ Pooled standard error of treatment means.

${ }^{3}$ P-Value for RFI x Time interaction. 

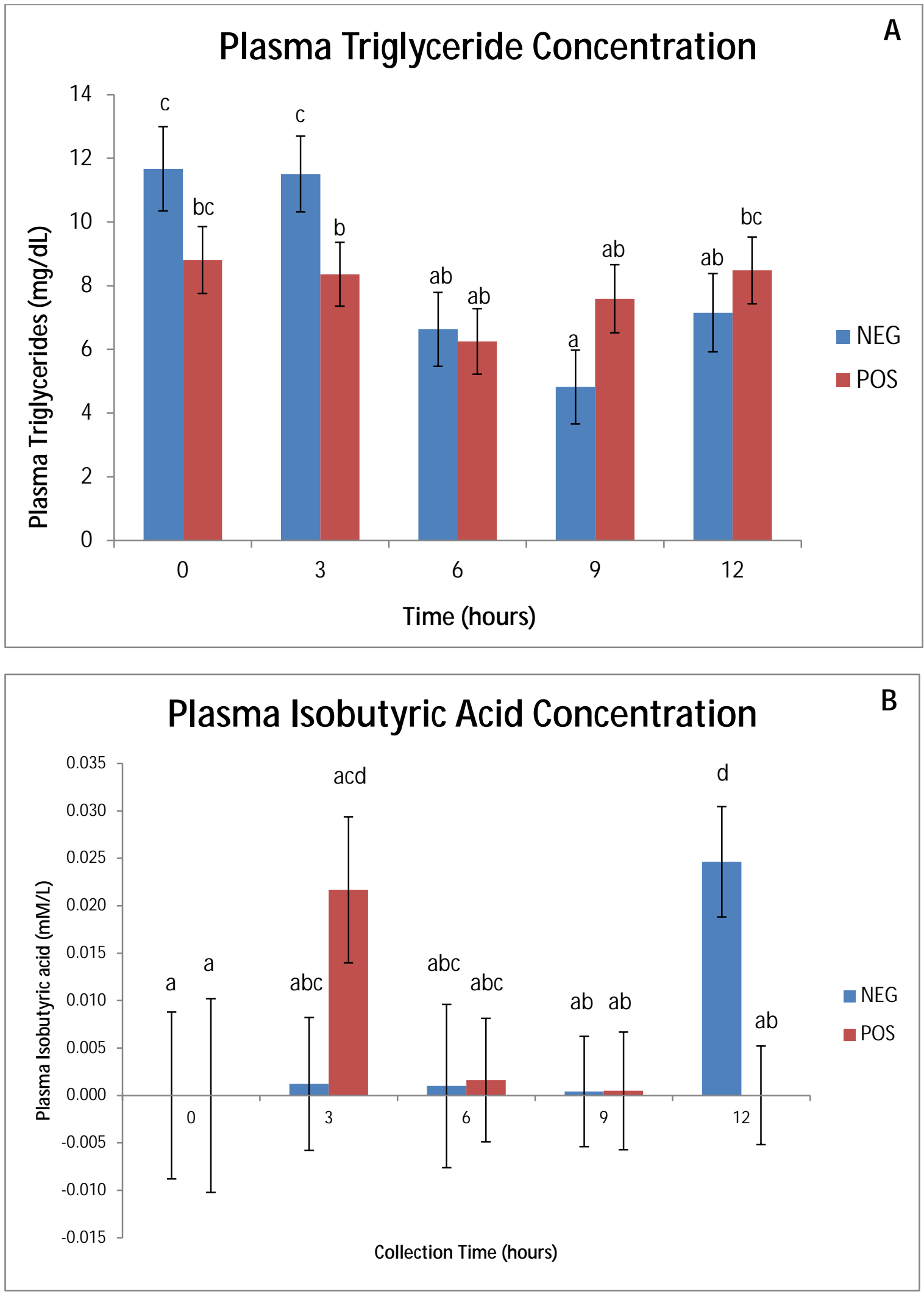

Figure 4. Plasma concentrations of triglycerides $(A)$ and isobutyric acid $(B)$ in steers immediately prior to feeding (Time 0 ) and at 3-hour intervals post-feeding (Times 3, 6, 9, and 12). Means with differing superscripts differ at $P<0.05$. 


\section{Experiments 2 and 3: Grazing_Dry Matter Intake and Digesta Rate of Passage}

Grazing voluntary DMI and DMI\%BW did not differ ( $\mathrm{P}=0.74$; Table 9) among

RFI classifications nor were they phenotypically correlated ( $\mathrm{P}=0.14$ and 0.24 , respectively; Table 10) to DRFI. Similarly, SPR did not differ $(\mathrm{P}=0.88)$ among RFI classifications. In contrast, LPR was greater in NEG RFI steers $(\mathrm{P}=0.04)$. Voluntary DMI intake and passage rate data and their phenotypic associations with DRFI are presented in Tables 9 and 10, respectively.

Table 9. Digesta rate of passage and voluntary dry matter intake while grazing in POSITIVE and NEGATIVE RFI steers.

\begin{tabular}{|c|c|c|c|c|}
\hline Trait $^{1}$ & POS & NEG & $\mathrm{SEM}^{2}$ & $P$-value \\
\hline $\mathrm{LPR}^{3}$ (\%/hour) & 6.32 & 7.16 & 0.0028 & 0.04 \\
\hline $\operatorname{SPR}^{3}$ (\%/hour) & 3.13 & 3.18 & 0.0020 & 0.88 \\
\hline PR Fecal DM & 17.18 & 17.10 & 0.21 & 0.78 \\
\hline DMI (kg/d) & 10.05 & 9.16 & 0.84 & 0.74 \\
\hline DMI\%BW & 1.94 & 1.87 & 0.15 & 0.74 \\
\hline Intake Fecal DM & 10.49 & 11.96 & 0.51 & 0.05 \\
\hline
\end{tabular}

\footnotetext{
${ }^{1} \mathrm{LPR}=$ liquid passage rate; $\mathrm{SPR}$ = solid passage rate; $\mathrm{PR}$ = passage rate; $\mathrm{DM}=$ dry matter; DMI = dry matter intake; DMI\%BW = dry matter intake as a percent of body weight.

${ }^{2}$ Pooled standard error of treatment means.

${ }^{3}$ Regression coefficients for marker concentration per gram of dry feces over time.
} 
Table 10. Phenotypic correlations between Dam RFI and measured traits in steer progeny for Experiments 2 and 3.

\begin{tabular}{lcc}
\hline \hline Trait $^{1}$ & $\mathrm{R}$ & $P$-value \\
\hline LPR & 0.56 & 0.04 \\
SPR & -0.02 & 0.94 \\
PR Fecal DM & -0.06 & 0.83 \\
DMI & 0.41 & 0.14 \\
DMI\%BW & 0.34 & 0.24 \\
Intake Fecal DM & -0.55 & 0.04 \\
\hline
\end{tabular}

${ }^{1} \mathrm{LPR}=$ liquid passage rate; SPR = solid passage rate; DMI = dry matter intake; DMI\%BW = intake as a percent of body weight.

\section{Experiment 4: Maintenance Feeding-Forage}

Rumen $\mathrm{pH}, \mathrm{NH}_{4}$, and VFA data for Experiment 4 are presented in Table 11. No differences were observed based on RFI classification. Although overall plasma TG concentrations were greater $(\mathrm{P}<0.01)$ and valeric acid tended $(\mathrm{P}=0.09)$ to be greater in NEG steers, POS steers exhibited greater overall urea nitrogen $(\mathrm{P}=0.02$; Table 12$)$. Similarly, UN was greater $(\mathrm{P}<0.01)$ in POS steers post-feeding and TG were greater $(\mathrm{P}$ $=0.01$ ) in NEG steers post-feeding (data not shown). No differences were observed in any other measured variables either overall or only during the post-feeding period based on RFI classification. The effect of RFI class over time was not significant for any of the measured variables. Overall plasma metabolite and VFA data are presented in Table 12. 
Table 11. Rumen $\mathrm{pH}$, ammonia, and volatile fatty acid concentrations among POSITIVE and NEGATIVE RFI steers for Experiment 4.

\begin{tabular}{lcccc}
\hline \hline Trait $^{1}$ & POS & NEG & SEM $^{2}$ & P-value \\
\hline Rumen pH & 6.83 & 6.83 & 0.04 & 0.98 \\
Rumen Ammonia (mg/dL) & 0.81 & 1.01 & 0.18 & 0.29 \\
Acetic acid (mM/L) & 60.32 & 60.32 & 2.16 & 0.99 \\
Propionic acid (mM/L) & 15.03 & 14.71 & 0.51 & 0.54 \\
Butyric acid (mM/L) & 7.43 & 7.17 & 0.27 & 0.36 \\
Isobutyric acid (mM/L) & 0.44 & 0.43 & 0.02 & 0.59 \\
Valeric acid (mM/L) & 0.49 & 0.46 & 0.03 & 0.27 \\
Isovaleric acid (mM/L) & 0.19 & 0.18 & 0.02 & 0.45 \\
Total VFA (mM/L) & 83.90 & 83.28 & 2.84 & 0.83 \\
Acetate:Propionate & 4.02 & 4.12 & 0.09 & 0.27 \\
\hline
\end{tabular}

${ }^{1} \mathrm{VFA}=$ volatile fatty acid

${ }^{2}$ Pooled standard error of treatment means. 
Table 12. Overall plasma metabolite and VFA concentrations in POSITIVE and NEGATIVE RFI steers for Experiment 4.

\begin{tabular}{lccccc}
\hline \hline Trait $^{1}$ & POS & NEG & SEM & P-value & RFI x Time \\
\hline ALB (g/dL) & 4.86 & 4.93 & 0.05 & 0.29 & 0.08 \\
UN (mg/dL) & 12.80 & 12.14 & 0.21 & 0.02 & 0.74 \\
CHOL (mg/dL) & 85.22 & 88.94 & 1.90 & 0.14 & 0.73 \\
GLU (mg/dL) & 69.99 & 70.45 & 1.03 & 0.73 & 0.68 \\
TG (mg/dL) & 15.02 & 16.59 & 0.42 & $<0.01$ & 0.36 \\
Acetic acid (mM/L) & 0.909 & 0.893 & 0.024 & 0.62 & 0.74 \\
Propionic acid (mM/L) & 0.015 & 0.017 & 0.001 & 0.28 & 0.15 \\
Butyric acid (mM/L) & 0.003 & 0.003 & 0.001 & 0.36 & 0.66 \\
Isobutyric acid (mM/L) & 0.001 & 0.001 & 0.001 & 0.91 & 0.93 \\
Valeric acid (mM/L) & 0.036 & 0.054 & 0.008 & 0.09 & 0.80 \\
Isovaleric acid (mM/L) & 0.023 & 0.020 & 0.004 & 0.59 & 0.28 \\
Total VFA's (mM/L) & 0.99 & 0.99 & 0.025 & 0.98 & 0.92 \\
Acetate:Propionate & 72.44 & 68.22 & 4.96 & 0.52 & 0.84 \\
Branched VFA's (mM/L) & 0.06 & 0.07 & 0.008 & 0.16 & 0.41 \\
\hline I & & 0.96 & \\
\hline
\end{tabular}

${ }^{1} \mathrm{ALB}=$ albumin; UN = urea nitrogen; $\mathrm{CHOL}=$ cholesterol; GLU = glucose; $\mathrm{TG}=$ triglycerides.

${ }^{2}$ Pooled standard error of treatment means.

${ }^{3} \mathrm{P}-$ Value for RFI x Time interaction. 


\section{Experiment 5: Maintenance Feeding-Concentrate}

Rumen $\mathrm{pH}, \mathrm{NH}_{4}$, and VFA data for Experiment 5 are presented in Table 13. No differences were observed based on RFI classification. Overall UN was greater in NEG steers $(\mathrm{P}=0.01)$ but all other plasma metabolites were similar among RFI groups (Table 14). A similar difference was observed for post-feeding UN ( $P=0.02$; data not shown). A tendency ( $\mathrm{P}=0.06$ ) for GLU to differ between RFI classes over time was observed, although the interaction of RFI with collection time was not significant for any of the other plasma variables. Plasma butyric acid and branched chain VFA concentrations were greater ( $\mathrm{P}=0.02$ and 0.02 , respectively) in NEG steers. Overall plasma metabolite and VFA data are presented in Table 14.

Table 13. Rumen $\mathrm{pH}$, ammonia, and volatile fatty acid concentrations among POSITIVE and NEGATIVE RFI steers for Experiment 5.

\begin{tabular}{lcccc}
\hline \hline Trait $^{1}$ & POS & NEG & SEM $^{2}$ & P-value \\
\hline Rumen pH & 6.61 & 6.72 & 0.05 & 0.11 \\
Rumen Ammonia (mg/dL) & 6.92 & 8.73 & 0.67 & 0.44 \\
Acetic acid (mM/L) & 61.24 & 60.62 & 2.94 & 0.88 \\
Propionic acid (mM/L) & 14.30 & 14.48 & 0.85 & 0.88 \\
Butyric acid (mM/L) & 13.23 & 13.73 & 1.17 & 0.76 \\
Isobutyric acid (mM/L) & 0.84 & 0.91 & 0.05 & 0.29 \\
Valeric acid (mM/L) & 0.71 & 0.67 & 0.05 & 0.55 \\
Isovaleric acid (mM/L) & 0.70 & 0.72 & 0.04 & 0.67 \\
Total VFA (mM/L) & 91.03 & 91.14 & 4.82 & 0.99 \\
Acetate:Propionate & 4.33 & 4.28 & 0.16 & 0.79 \\
\hline${ }^{1}$ VFA = volatile fatty acid & & & & \\
${ }^{2}$ Pooled standard error of treatment means. & & & \\
& & & & \\
\hline
\end{tabular}


Table 14. Overall plasma metabolite and VFA concentrations in POSITIVE and NEGATIVE RFI steers for Experiment 5.

\begin{tabular}{|c|c|c|c|c|c|}
\hline Trait $^{1}$ & POS & NEG & SEM $^{2}$ & $P$-value & RFI x Time ${ }^{3}$ \\
\hline ALB (g/dL) & 5.00 & 5.05 & 0.05 & 0.48 & 0.11 \\
\hline $\mathrm{UN}(\mathrm{mg} / \mathrm{dL})$ & 15.42 & 16.74 & 0.38 & 0.01 & 0.47 \\
\hline CHOL (mg/dL) & 82.19 & 77.60 & 1.58 & 0.64 & 0.89 \\
\hline GLU (mg/dL) & 83.91 & 84.31 & 1.03 & 0.77 & 0.06 \\
\hline TG (mg/dL) & 25.13 & 23.34 & 1.09 & 0.23 & 0.52 \\
\hline Acetic acid (mM/L) & 0.550 & 0.494 & 0.043 & 0.35 & 0.57 \\
\hline Propionic acid (mM/L) & 0.011 & 0.005 & 0.004 & 0.20 & 0.85 \\
\hline Butyric acid (mM/L) & 0.008 & 0.005 & 0.001 & 0.02 & 0.92 \\
\hline Isobutyric acid (mM/L) & 0.001 & 0.000 & 0.000 & 0.07 & 0.37 \\
\hline Valeric acid (mM/L) & 0.000 & 0.000 & 0.000 & 1.00 & 1.00 \\
\hline Isovaleric acid (mM/L) & 0.002 & 0.002 & 0.001 & 0.74 & 0.53 \\
\hline Total VFA's (mM/L) & 0.573 & 0.505 & 0.461 & 0.29 & 0.63 \\
\hline Acetate:Propionate & 46.844 & 96.015 & 18.624 & 0.34 & 0.89 \\
\hline Branched VFA’s (mM/L) & 0.011 & 0.007 & 0.001 & 0.02 & 0.43 \\
\hline
\end{tabular}

${ }^{1}$ ALB = albumin; UN = urea nitrogen; $\mathrm{CHOL}=$ cholesterol; $\mathrm{GLU}=$ glucose; $\mathrm{TG}=$ triglycerides.

${ }^{2}$ Pooled standard error of treatment means.

${ }^{3} \mathrm{P}-$ Value for RFI $\mathrm{x}$ Time interaction. 


\section{DISCUSSION}

\section{General}

Although dam RFI was used to classify steers as efficient or inefficient in this series of experiments, production and body composition traits reported in Experiment 1 exhibited similar relationships to RFI as would be expected in a population in which phenotypic RFI had actually been measured. Steers did not differ in birth weight, weaning weight, age, on-test BW, off-test BW, or ADG based on RFI classification and no phenotypic correlations were observed with DRFI. However, steers classified as POS did possess more RUF (42.23 vs. $29.63 \mathrm{~mm}$, respectively; $\mathrm{P}=0.02$ ) at the end of Experiment 1 than NEG steers. Although not significant, both RIF and RUF tended to be correlated positively with dam RFI ( $\mathrm{r}=0.47$ and $0.51 ; \mathrm{P}=0.09$ and 0.06 , respectively) at the conclusion of Experiment 1. These data are in agreement with the literature, which indicates that RFI is independent of its component traits and positively related to measures of body fat (Arthur et al., 2001; Basarab et al., 2003; Shaffer et al., 2011). These data indicate that steers were classified accurately based on efficiency phenotype of the dam, even though cow RFI is only moderately related to progeny RFI $(r=0.30$; Basarab et al., 2007). The fact that steers were all progeny of the same sire and from related dams likely reduced paternal variation in RFI and strengthened the relationship between progeny RFI and dam RFI as well. 


\section{Rumen pH, $\mathrm{NH}_{4}$ and VFAs}

Although previous reports have indicated that microbial population and ruminal efficiency may differ among RFI classifications in cattle (Nkrumah et al., 2006), no differences were observed in rumen $\mathrm{pH}, \mathrm{NH}_{4}$, or VFA concentrations. This was true whether steers were fed ad libitum or at maintenance with forage or concentrate diets. In agreement with the present experiments, Lawrence et al. (2011) reported that rumen fluid $\mathrm{pH}$, total VFA, acetic acid, and butyric acid did not differ among RFI groups of gestating yearling heifers classified as either High, Medium, or Low RFI. Similarly, Kreuger et al. (2009) reported that RFI classes did not differ in rumen $\mathrm{pH}$ or VFA concentration. In contrast, Lawrence et al. (2011) reported that rumen $\mathrm{NH}_{4}$, propionic acid, and acetate:propionate ratio differed based on RFI classification. Additionally, rumen propionate concentration increased as RFI decreased further indicating that rumen microbial populations may differ based on RFI classification (Lawrence et al., 2011). Although this seems likely and has been reported in mice selected for high and low heat loss (Nielsen et al., 2009), the data in the present study do not indicate such an association.

\section{Plasma VFA's and Metabolites}

In general, plasma metabolite and VFA concentrations did not differ based on RFI classification. However, valeric acid concentrations were greater $(P=0.02)$ in NEG steers in Experiment 1 and tended $(\mathrm{P}=0.06)$ to be greater when limit fed a forage diet in Experiment 4. No other differences were observed between overall or post-feeding plasma VFA concentrations in Experiments 1 and 4. This was also true for plasma 
metabolites for Experiment 1. Lawrence et al. (2011) reported that ALB, GLU, UN, and TG did not differ based on RFI classification. Similarly, Kelly et al. (2010a) reported that UN and GLU concentrations did not differ between High, Medium, and Low RFI Limousin X Holstein heifers. However, Kelly et al. (2010b) reported a positive correlation $(r=0.38$; $\mathrm{P}<0.01)$ between RFI and UN in heifers consuming a corn-silagebased diet. In agreement with this relationship, overall and post-feeding UN are greater $(\mathrm{P}=0.02)$ in POS RFI steers when steers were limit fed a forage diet; however, when limit fed a concentrate diet, UN was greater $(\mathrm{P}=0.01)$ in NEG steers, indicating that UN may be influenced by the interaction of RFI with diet type and/or feeding level, as the steers in the present experiments were limit fed and the heifers in Kelly et al. (2010a; 2010b) and Lawrence et al. (2011) were fed ad libitum.

Interestingly, there were differences in plasma VFA when steers were limit fed a concentrate diet in Experiment 5. Butyric acid and overall branched chain VFA were greater in NEG steers ( $\mathrm{P}=0.02$ and 0.02 , respectively) although no differences existed for individual branched chain VFA. Around $90 \%$ of rumen produced butyric acid is metabolized by the epithelium of the rumen and omasum where it is converted to acetoacetate and $\beta$-hydroxybutyrate and utilized for energy (van Houtert, 1993; Kristensen et al., 1998). Greater plasma concentrations of butyric acid in NEG RFI steers may indicate a lower energy requirement by the splanchnic tissues but could be the result of interactions between VFA during activation. Ash and Baird (1973) reported that propionate can inhibit butyrate activation in rumen epithelium but has a much stronger inhibition in the liver ensuring that butyrate is metabolized by the rumen epithelium and propionate by the liver. Still, the greater plasma concentration in NEG steers without a 
difference in rumen butyric acid concentration indicates that ruminal absorption is greater in NEG RFI steers. In contrast, the difference in branched chain VFA may indicate a more efficient microbial fermentation of protein as branched chain VFA are products of branched chain amino acid fermentation (Garton, 1977). Nonetheless, concentrations of butyrate and branched chain VFA in both RFI classes were similar to previous reports (Krehbeil et al., 1992; Reynolds et al., 1992) and no reports in the literature have attempted to relate plasma VFA concentration to RFI class to date.

Plasma metabolite and VFA concentrations did not differ significantly with respect to collection time when steers were limit fed either forage or concentrate; however, there was a tendency for this effect with GLU when steers were fed a concentrate diet. When fed a forage-based diet ad libitum in Experiment 1, the interaction between RFI and collection time was significant for both TG and isobutyric acid. Although POS RFI steers had greater concentrations of TG at 3 hours post-feeding, they did not differ at any of the other time points. To date, there are no reports to which these data can be compared in cattle; nonetheless, these data may indicate a greater lipid absorptive capacity or a liver that is more efficient at packaging lipids to be sent to peripheral tissues. However, it is important to note that this effect was not significant for cholesterol and it may be just an artifact of an infrequent sampling regimen.

\section{Grazing Intake and Passage Rate}

Low RFI animals consume less feed than High RFI animals in confinement (Arthur et al., 2001a) and have been reported to consume numerically smaller amounts of forage during grazing (Meyer et al., 2008). However, due to the difficulty and error associated with measuring intake while grazing, there have been no other attempts to 
measure how RFI relates to grazing intake on pasture. In the present series of studies, grazing forage intake for the 14 steers was estimated in Experiment 2. Similar to the report by Meyer et al. (2008), NEG RFI steers consumed 8.9 \% less DM per day than their POS RFI contemporaries on a numerical basis, but this difference was not significant. Nonetheless, fecal DM was significantly $(\mathrm{P}=0.05)$ lower in POS steers during the intake measurement period indicating that water absorption was deterred most likely by a greater rate of passage. Passage rate is positively associated with feed intake (Baile and Della-Fera, 1981), so these data provide anecdotal evidence in agreement with the numeric difference in DMI. Although these data indicate that selection for RFI could potentially reduce voluntary DMI while grazing, significance is not likely to be obtained with small numbers due to limitations in the methodology for measuring grazing intake. In addition to estimating forage intake, LPR and SPR data were collected while grazing fall regrowth, cool season grass pastures. Solid phase passage rate did not differ based on RFI classification while LPR was greater in NEG RFI steers. These data may indicate differences in physiological regulation of GIT contraction. However, nutrients in solution are more readily available to the animal, so it may be possible that NEG RFI cattle achieve greater efficiency by increasing the flow of nutrient rich rumen fluid to the small intestine rather than having it remain in the rumen where further microbial digestion may increase energy and/or nutrient waste. Evidence supporting this concept has been reported by Meng et al. (1999) who indicated that rumen microbial efficiency increased as dilution rate increased in vitro. Similarly, Fu et al. (2001) reported that microbial efficiency was greatest at the highest rate of liquid passage in vivo. Thus, the increase in LPR in NEG steers may indicate a more efficient rumen microbial population. 


\section{CONCLUSION}

Residual feed intake is related positively to liquid phase passage rate in steers while grazing, which may indicate differential regulation of GIT physiology by differing RFI groups. Differential regulation of GIT physiology could result in differing populations and/or efficiencies of rumen microorganisms between RFI classes. Although the rumen data do not indicate such a difference, the reversal of differences in UN among RFI classes when fed different diets indicates that microbial population may indeed differ among RFI class or that the absorptive capacity of the GIT varies with diet or with the interaction of diet and RFI class. The lack of pre-feeding differences in plasma VFA's and metabolites further indicates that post-feeding differences may be the result of variation in the absorptive capacity of the GIT. It is likely that a greater portion of the variation in RFI is related to the absorptive capacity and/or energy requirements of the GIT, which may be dependent upon diet type. 


\section{LITERATURE CITED}

Adam, I., B. A. Young, A. M. Nicol, and A. A. Degan. 1984. Energy cost of eating in young cattle given diets of different form. Anim. Prod. 38:53-56.

Archer, J. A., Arthur, P.F., Herd, R. M., Parnell, P.F. and Pitchford, W.S., 1997. Optimum postweaning test for measurement of growth rate, feed intake, and feed efficiency in British breed cattle. J. Anim. Sci. 75, 2024-2032.

Archer, J. A., W. S. Pitchford, T. E. Hughes, and P. F. Parnell. 1998. Genetic and phenotypic relationships between food intake, growth, efficiency and body composition of mice postweaning and at maturity. Anim. Sci. 67:171-182.

Archer, J. A., E. C. Richardson, R. M. Herd and P. F. Arthur. 1999. Potential for selection to improve feed efficiency in British-bred cattle: A review. Aust. J. of Agric. Res. 50:147-161.

Archer, J. A., and L. Bergh. 2000. Duration of performance tests for growth rate, feed intake and feed efficiency in four biological types of beef cattle. Livest. Prod. Sci. 65:47-55.

Archer, J. A., A. Reverter, R. M. Herd, D. J. Johnston, and P. F. Arthur. 2002. Genetic variation in feed intake and efficiency of mature beef cows and relationships with postweaning measurements. Proc. 7th World Congress on Genetics Applied to Livestock Production 31:221-224.

Arthur, P. F., G. Renand and D. Krauss. 2001a. Genetic and phenotypic relationships among different measures of growth and feed efficiency in young Charolais bulls. Livest. Prod. Sci. 68:131-139.

Arthur, P. F., J. A. Archer, D. J. Johnston, R. M. Herd, E. C. Richardson and P. F. Parnell. 2001b. Genetic and phenotypic variance and covariance components for feed intake, feed efficiency and other postweaning traits in Angus cattle. J. Anim. Sci. 79:2805-2811.

Arthur, P. F., J. A. Archer, A. Reverter, D. J. Johnston and R. M. Herd. 2004. Genetic correlations between postweaning feed efficiency and cow traits. J. Anim. Sci. 82(Suppl. 1):449.

Arthur, P. F., R. M. Herd, J. F. Wilkins and J. A. Archer. 2005. Maternal productivity of Angus cows divergently selected for post-weaning residual feed intake. Aust. J. of Exp. Agr. 45:985-993. 
Ash, R. and G. D. Baird. 1973. Activation of volatile fatty acids in bovine liver and rumen epithelium. Biochem. J. 136:311-319.

Baile, C. A. and Della-Fera, M. A. 1981. Nature of hunger and satiety control systems in ruminants. J. Dairy Sci. 64: 1140-1152.

Barea, R., S. Dubois, H. Gilbert, P. Sellier, J. van Milgen and J. Noblet. 2010. Energy utilization in pigs selected for high and low residual feed intake. J. Anim. Sci. 88:2062-2072.

Basarab, J. A., M. A. Price, J. L. Aalhus, E. K. Okine, W. M. Snelling and K. L. Lyle. 2003. Residual feed intake and body composition in young growing cattle. Can. J. Anim. Sci. 83:189-204.

Basarab, J. A., D. McCartney, E. K. Okine and V. S. Baron. 2007. Relationships between progeny residual feed intake and dam productivity traits. Can. J. Anim. Sci. 87:489-502.

Basarab, J. A, M. G. Colazo, D. J. Ambrose, S. Novak, D. McCartney, and V. S. Baron. 2011. Residual feed intake adjusted for backfat thickness and feeding frequency is independent of fertility in beef heifers. Can. J. Anim. Sci. 91:573-584.

Berry, D. P. and J. J. Crowley. 2012. Residual intake and body weight gain: A new measure of efficiency in growing cattle. J. Anim. Sci. 90:109-115.

Bingham, G. M., T. H. Friend, P. A. Lancaster and G. E. Carstens. 2009. Relationship between feeding behavior and residual feed intake in growing Brangus heifers. J. Anim. Sci. 87:2685-2689.

Blaxter, K. L. 1962. The Energy Metabolism of Ruminants. Springfield, Illinois: Thomas.

Braastad, B. O., and J. Katle. 1989. Behavioural differences between laying populations selected for high and low efficiency of food utilisation. Br. Poult. Sci. 30:533544.

Boddicker, N., N. K. Gabler, M. E. Spurlock, D. Nettleton, and J. C. M. Dekkers. 2011. Effects of ad libitum and restricted feed intake on growth performance and body composition of Yorkshire pigs selected for reduced residual feed intake. J. Anim. Sci. 89:40-51.

Bottje, W. G., and G. E. Carstens. 2009. Association of mitochondrial function and feed efficiency in poultry and livestock species. J. Anim. Sci. 87(E. Suppl.):E48-E63.

Brody, S. 1945. Bioenergetics and Growth. New York: Hafner. 
Bunger, L., M. G. MacLeod, C. A. Wallace, and W. G. Hill. 1998. Direct and correlated effects of selection for food intake corrected for body weight in the adult mouse. Proc. 6th World Congr. Genet. Appl. Livest. Prod., Univ. New England, Armidale, Australia 26:97-100.

Byerly, T. C. 1941. Feed and other costs of producing market eggs. Bull. A1 (Technical). Univ. Maryland Agric. Exp. Stn., College Park, MD.

Cai, W., D. S. Casey, and J. C. M. Dekkers. 2008. Selection response and genetic parameters for residual feed intake in Yorkshire swine. J. Anim. Sci. 86:287-298.

Cant, J. P., B. W. McBride, and W. J. Croom. 1996. The regulation of intestinal metabolism and its impact on whole animal energetics. J. Anim. Sci. 74:25412553.

Castro Bulle, F. C. P., P. V. Paulino, A. C. Sanches and R. D. Sainz. 2007. Growth, carcass quality, and protein and energy metabolism in beef cattle with different growth potentials and residual feed intakes. J. Anim. Sci. 85:928-936.

Cattle Learning Center. Beef Industry Statistics. National Cattlemen's Beef Association. Denver, CO., 2011.

Channon, A. F., J. B. Rowe and R. M. Herd. 2004. Genetic Variation in starch digestion in feedlot cattle and its association with residual feed intake. Aust. J. of Exp. Agr. 44:469-474.

Crews, D. H. Jr., 2005. Genetics of efficient feed utilization and national cattle evaluation: a review. Genet. Mol. Res. 4:152-165.

Crowley, J. J., M. McGee, D. A. Kenny, D. H. Crews Jr., R. D. Evans, and D. P. Berry. 2010. Phenotypic and genetic parameters for different measures of feed efficiency in different breeds of Irish performance-tested beef bulls. J. Anim. Sci. 88:885894.

Cruz, G. D., J. A. Rodriguez-Sanchez, J. W. Oltjen and R. D. Sainz. 2010. Performance, residual feed intake, digestibility, carcass traits, and profitability of AngusHereford steers housed in individual or group pens. J. Anim. Sci. 88:324-329.

de Haer, L. C. M., P. Luiting, and H. L. M. Aarts. 1993. Relations among individual (residual) feed intake, growth performance and feed intake pattern of growing pigs in group housing. Livest. Prod. Sci. 36:233-253.

Dobos, R. and R. Herd. 2008. Spectral analysis of feeding patterns of steers divergent in residual feed intake. Aust. J. of Exp. Agric. 48:843-846. 
Donoghue, K. A., P. F. Arthur, J. F. Wilkins and R. M. Herd. 2011. Onset of puberty and early-life reproductive in Angus females divergently selected for post-weaning residual feed intake. Anim. Prod. Sci. 51:183-190.

Durunna, O. N., F. D. N. Mujibi, L. Goonewardene, E. K. Okine, J. A. Basarab, Z. Wang, and S. S. Moore. 2011a. Feed efficiency differences and reranking in beef steers fed grower and finisher diets. J. Anim. Sci. 89:158-167.

Durunna, O. N., Z. Wang, J. A. Basarab, E. K. Okine, and S. S. Moore. 2011. Phenotypic and genetic relationships among feeding behavior traits, feed intake, and residual feed intake in steers. J. Anim. Sci. 89:3401-3409.

Durunna, O. D., M. G. Colazo, D. J. Ambrose, D. McCartney, V. S. Baron and J. A. Basarab. 2012. Evidence of residual feed intake reranking in crossbred replacement heifers. J. Anim. Sci. 90:734-741.

Eisemann, J. H., and J. A. Nienaber. 1990. Tissue and whole-body oxygen uptake in fed and fasted steers. Br. J. Nutr. 64:399-411.

Elzo, M. A., D. G. Riley, G. R. Hansen, D. D. Johnson, R. O. Meyer, S. W. Coleman, C. C. Chase, J. G. Wasdin and J. D. Driver. Effect of breed composition on phenotypic residual feed intake and growth in Angus, Brahman, and Angus $\mathrm{x}$ Brahman crossbred cattle. J. Anim. Sci. 87:3877-3886.

Ferrell, C. L., and T. G. Jenkins. 1985a. Energy utilization by Hereford and Simmental males and females. Anim. Prod. 41:53-61.

Fitzhugh, H. A., Jr., and C. S. St. Taylor. 1971. Genetic analysis of degree of maturity. J. Anim. Sci. 33:717-725.

Foster, W. H., D. J. Kilpatrick, and I. H. Heaney. 1983. Genetic variation in the efficiency of energy utilization by the fattening pig. Anim. Prod. 37:387-393.

Fu, C. J., E. E. Felton, J. W. Lehmkuhler and M. S. Kerley. 2001. Ruminal peptide concentration required to optimize microbial growth and efficiency. J. Anim. Sci. 79:1305-1312.

Garrett, W. N. 1971. Energetic efficiency of beef and dairy steers. J. Anim. Sci. 32:451456.

Garton, G. A. 1977. Fatty acid metabolism in ruminants. Page 337- 370 in Biochemistry of Lipids II. T. W. Goodwin, ed. Univ. Park Press, Baltimore, MD. 
Gilbert, H., J. P. Bidanel, J. Gruand, J. C. Caritez, Y. Billon, and P. Guillouet. 2007. Genetic parameters for residual feed intake in growing pigs, with emphasis on genetic relationships with carcass and meat quality traits. J. Anim. Sci. 85:31823188.

Gilbert, H., J.-P. Bidanel, Y. Billon, H. Lagant, P. Guillouet, P. Sellier, J. Noblet, and S. Hermesch. 2012. Correlated responses in sow appetite, residual feed intake, body composition, and reproduction after divergent selection for residual feed intake in the growing pig. J. Anim. Sci. 90:1097-1108.

Goonewardene, L. A., E. Okine, Z. Wang, D. Spaner, P. S. Mir, Z. Mir and T. Marx. 2004. Residual metabolizable energy intake and its association with test duration. Can. J. Anim. Sci. 84:291-295.

Gregory, K. E. 1972. Beef cattle type for maximum efficiency 'Putting it all together'. J. Anim. Sci. 34:881-884.

Grobet, L., L. J. R. Martin, D. Poncelet, D. Priottin, B. Brouwers, J. Riquet, A. Schoeberlein, S. Dunner, F. Ménissier, J. Massabanda, R. Fries, R. Hanset, and M. Georges. 1997. A deletion in the bovine myostatin gene causes the doublemuscle phenotype in cattle. Nat. Genet. 17:71-74.

Gunsett, F. C. 1984. Linear index selection to improve traits defined as ratios. J. Anim. Sci. 63:111-119.

Hegarty, R. S., J. P. Goopy, R. M. Herd and B. McCorkell. 2006. Cattle selected for lower residual feed intake have reduced daily methane production. J. Anim. Sci. 85:1475-1486.

Herd, R. M., E. C. Richardson, R. S. Hegarty, R. Woodgate, J. A. Archer and P. F. Arthur. 1998. Pasture intake by high versus low net feed efficient Angus cows. Anim. Prod. In Aust. 22:137-140.

Herd, R. M., and S. C. Bishop. 2000. Genetic variation in residual feed intake and its association with other production traits in British Hereford cattle. Livest. Prod. 59:1185-1193.

Herd, R. M., Arthur, P. F., Hegarty, R. S. and Archer, J. A. 2002. Potential to reduce greenhouse gas emissions from beef production by selection for reduced residual feed intake. 7th Wld. Congr. Genet. Appl. Livest. Prod. 31: 281-284.

Herd, R. M., V. H. Oddy and E. C. Richardson. 2004. Biological basis for variation in residual feed intake in beef cattle. 1. Review of potential mechanisms. Aust. J. of Exp. Agric. 44:423-430. 
Herd, R. M., P. F. Arthur, and J. A. Archer. 2006. Repeatability of residual feed intake and interaction with level of nutrition in Angus cows. 26th Biennial Conference of Australian Society of Animal Production. No. 80.

Herd, R. M., and P. F. Arthur. 2009. Physiological basis for residual feed intake. J. Anim. Sci. 87:E64-E71.

Hoque, M. A., H. Kadowaki, T. Shibata, T. Oikawa, and K. Suzuki. 2007. Genetic parameters for measures of the efficiency of gain of boars and the genetic relationships with its component traits in Duroc pigs. J. Anim. Sci. 85:1873-1879.

Hoque, M. A., M. Hosono, T. Oikawa and K. Suzuki. 2009a. Genetic parameters for measures of energetic efficiency of bulls and their relationships with carcass traits of field progeny in Japanese Black cattle. J. Anim. Sci. 87:99-106.

Hoque, M. A., K. Katoh, and K. Suzuki. 2009b. Genetic associations of residual feed intake with serum insulin-like growth factor-I and leptin concentrations, meat quality, and carcass cross sectional fat area ratios in Duroc pigs. J. Anim. Sci. 87:3069-3075.

Houtert, M. F. J. van. 1993. The production and metabolism of volatile fatty acids by ruminants fed roughages: A review. Anim. Feed Sci. and Tech. 43:189-225.

Jensen, J., I. L. Mao, B. B. Andersen and P. Madsen. 1992. Phenotypic and genetic relationships between residual energy intake and growth, feed intake, and carcass traits of young bulls. J. Anim. Sci. 70:386-395.

Johnson, Z. B., J. J. Chewning and R. A. Nugent, $3^{\text {rd }}$. 1999. Genetic Parameters for Production Traits and Measures of Residual Feed Intake in Large White Swine. J. Anim. Sci. 77:1679-1685.

Karimi, A. R., F. N. Owens and G. W. Horn. 1987. Simultaneous extraction of Yb, Dy and Co from feces with DCTA, DPTA or EDTA. Oklahoma Ag. Exp. Station Anim. Sci. Research Report. 1987:118-126.

Katle, J. 1991. Selection for efficiency of food utilisation in laying hens: Causal factors for variation in residual food consumption. Br. Poult. Sci. 32:955-969.

Kellner, O. 1909. The Scientific Feeding of Animals. McMillan Company, New York.

Kelly, A. K., M. McGee, D. H. Crews Jr., A. G. Fahey, A. R. Wylie and D. A. Kenny. 2010a. Effect of divergence in residual feed intake on feeding behavior, blood metabolic variables, and body composition traits in growing beef heifers. J. Anim. Sci. 88:109-123. 
Kelly, A. K., M. McGee, D. H. Crews, Jr., T. Sweeney, T. M. Boland, and D. A. Kenny. 2010b. Repeatability of feed efficiency, carcass ultrasound, feeding behavior, and blood metabolic variables in finishing heifers divergently selected for residual feed intake. J. Anim. Sci. 88:3214-3225.

Knott, S. A., L. J. Cummins, F. R. Dunshea, and B. J. Leury. 2008. Rams with poor feed efficiency are highly responsive to an exogenous adrenocorticotropin hormone (ACTH) challenge. Domest. Anim. Endocrinol. 34:261-268.

Klieber, M. 1947. Body Size and metabolic rate. Physiol. Rev. 27:511-541.

Koch, R. M., L. A. Swiger, D. Chambers and K. E. Gregory. 1963. Efficiency of feed use in cattle. J. Anim. Sci. 22:486-494.

Kolath, W. H., M. S. Kerley, J. W. Golden and D. H. Keisler. 2006a. The relationship between mitochondrial function and residual feed intake in Angus steers. J. Anim. Sci. 84:861-865.

Kolath, W. H., M. S. Kerley, J. W. Golden, S. A. Shahid and G. S. Johnson. 2006b. The relationships among mitochondrial uncoupling protein 2 and 3 expression, mitochondrial deoxyribonucleic acid single nucleotide polymorphisms, and residual feed intake in Angus steers. J. Anim. Sci. 84:1761-1766.

Koots, K. R., and J. P. Gibson. 1998. Economic values for beef production traits from a herd level bioeconomic model. Can. J. Anim. Sci. 78:29-45.

Krehbeil, C. R., D. L. Harmon and J. E. Scheider. 1992. Effect of increasing ruminal butyrate on portal and hepatic nutrient flux in steers. J. Anim. Sci. 70:904-914.

Kristensen, N. B., A. Danfaer and N. Agergaard. 1998. Absorption and metabolism of short-chain fatty acids in ruminants. Arch. Anim. Nutr. 51:165-175.

Krueger, W. K., G. E. Carstens, Z. D. Paddock, T. R. Calloway, R. C. Anderson, N. A. Kreuger, V. Gontcharova, S. E. Dowd, R. R. Gomez, and W. E. Pinchak. 2009. Associations between feed efficiency and gut microbial ecology and fermentation parameters in feedlot cattle. J. Anim. Sci. 87(E-Suppl. 2):T312. (Abstr.)

Lancaster, P. A., G. E. Carstens, F. R. B. Ribeiro, M. E. Davis, J. G. Lyons and T. H. Welsh, Jr. 2008. Effects of divergent selection for serum insulin-like growth factor-I concentration on performance, feed efficiency, and ultrasound measures of carcass composition traits in Angus bulls and heifers. J. Anim. Sci. 86:28622871. 
Lancaster, P. A., G. E. Carstens, F. R. B. Ribeiro, L. O. Tedeschi and D. H. Crews, Jr. 2009a. Characterization of feed efficiency traits and relationships with feeding behavior and ultrasound carcass characteristics in growing bulls. J. Anim. Sci. 87:1528-1539.

Lancaster, P. A., G. E. Carstens, D. H. Crews Jr., T. H. Welsh Jr., T. D. A. Forbes, D. W. Forrest, L. O. Tedeschi, R. D. Randel and F. M. Rouquette. 2009b. Phenotypic and genetic relationships of residual feed intake with performance and ultrasound carcass characteristics of Brangus heifers. J. Anim. Sci. 87:3887-3896.

Lawrence, P., D. A. Kenny, B. Earley, D. H. Crews Jr., and M. McGee. 2011. Grass silage intake, rumen and blood variables, ultrasonic and body measurements, feeding behavior, and activity in pregnant beef heifers differing in phenotypic residual feed intake. J. Anim. Sci. 89:3248-3261.

Lee, H. J., M. A. Khan, W. S. Lee, S. H Yang, S. B. Kim, K. S. Ki, H. S. Kim, J. K. Ha, and Y. J. Choi. 2009. Influence of equalizing the gross composition of milk replacer to that of whole milk on the performance of Holstein calves. J. Anim. Sci. 87:1129-1137.

Lefaucheur, L. B. Lebret, P. Ecolan, I. Louveau, M. Damon, A. Prunier, Y. Billon, P. Sellier, and H. Gilbert. 2011. Muscle characteristics and meat quality traits are affected by divergent selection on residual feed intake in pigs. J. Anim. Sci. 89:996-1010.

Lents, C. A., R. D. Randel, A. M. Stelzleni, L. C. Caldwell, and T. H. Welsh, Jr. 2011. Function of the corpus luteum in beef heifers is affected by acute submaintenance feeding but is not correlated with residual feed intake. J. Anim. Sci. 89:40234031.

Liu, M. F., L. A. Goondwardene, D. R. C. Bailey, J. A. Basarab, R. A. Kemp, P. F. Arthure, E. K. Okine and M. Makarechian. 2000. A study on the variation of feed efficiency in station tested beef bulls. Can. J. Anim. Sci. 80: 435-441.

Lodge-Ivey, S. L., J. Browne-Silva, and M. B. Horvath. Technical note: Bacterial diversity and fermentation end products in rumen fluid samples collected via oral lavage or rumen cannula. J. Anim. Sci. 87:2333-2337.

Lofgreen, G. P. and W. N. Garrett. 1968. A system for expressing net energy requirements and feed values for growing and finishing cattle. J. Anim. Sci. 27:793-806.

Luiting, P. 1990. Genetic variation of energy partitioning in laying hens: Causes of variation in residual feed consumption. World’s Poult. Sci. J. 46:133-152. 
Luiting, P., J. W. Schrama, W. Van der Hel, and E. M. Urff. 1991a. Metabolic differences between white leghorns selected for high and low residual feed consumption. Br. Poult. Sci. 32:763-782.

Luiting, P., J. W. Schrama, W. van Der Hel, E. M. Urff, P. G. J. J. van Boekholt, E. M. W. van Den Elsen, and M. W. A. Verstegen. 1991b. Metabolic differences between white leghorns selected for high and low residual feed consumption. Pages 384-387 in Energy Metabolism of Farm Animals. C. Wenk and M. Boessinger, ed. Eur. Assoc. Anim. Prod. Publ. 58, Kartause, Switzerland.

Luiting, P., and E. M. Urff. 1991. Residual feed consumption in laying hens. 2. Genetic variation and correlations. Poult. Sci. 70:1663-1672.

Luiting, P., E. M. Urff, and M. W. A. Verstegen. 1994. Between animal variation in biological efficiency as related to residual feed consumption. Neth. J. Agric. Sci. 42:59-67.

Mader, C. J., Y. R. Montanholi, Y. J. Wang, S. P. Miller, I. B. Mandell, B. W. McBride and K. C. Swanson. 2009. Relationships among measures of growth performance and efficiency with carcass traits, visceral organ mass, and pancreatic digestive enzymes in feedlot cattle. J. Anim. Sci. 87:1548-1557.

Meng, Q., M. S. Kerley, P. A. Ludden, and R. L. Belyea. 1999. Fermentation substrate and dilution rate interact to affect microbial growth and efficiency. J. Anim. Sci. 77:206-214.

Meyer, A. M., M. S. Kerley and R. L. Kallenbach. 2008. The effect of residual feed intake classification on forage intake by grazing beef cows. J. Anim. Sci. 86:2670-2679.

Montano-Bermudez, M., M. K. Neilsen and G. Deutscher. 1990. Energy requirements for maintenance of crossbred beef cattle with different genetic potential for milk. J. Anim. Sci. 68:2279-2288.

Mousel, M. R., W. W. Stroup, and M. K. Nielsen. 2001. Locomotor activity, core body temperature, and circadian rhythms in mice selected for high and low heat loss. J. Anim. Sci. 79:861-868.

Muro-Reyes, A., H. Gutierrez-Banuelos, L. H. Diaz-Garcia, F. J. Gutierrez-Pina, L. M. Escareno-Sanchez, R. Banuelos-Valenzuela, C. A. Medina-Flores and A. Corral Luna. 2011. Potential environmental benefits of residual feed intake as strategy to mitigate methane emissions in sheep. J. Anim. and Vet. Adv. 10(12):1551-1556.

National Research Council. 1996 (2000 Update). Nutrient Requirements of Beef Cattle. 7th ed. Natl. Acad. Press, Washington, DC. 
Nguyen, N. H., C.P. McPhee and C.M. Wade. 2005. Responses in residual feed intake in lines of Large White pigs selected for growth rate on restricted feeding (measured on ad libitum individual feeding). J. Anim. Breed. \& Genet. 122:264-270.

Nielsen, M., R. Griess, J. Walter, and A. Benson. 2009. Gut microbial population differently affects feed intake in mice lines selected for high and low heat loss. J. Anim. Sci. 87(E Suppl. 3):52.

Nkrumah, J. D., J. A. Basarab, M. A. Price, E. K. Okine, A. Ammoura, S. Guercio, C. Hansen, C. Li, B. Benkel, B. Murdoch and S. S. Moore. 2004. Different measures of energetic efficiency and their phenotypic relationships with growth, feed intake, and ultrasound and carcass merit in hybrid cattle. J. Anim. Sci. 82:24512459.

Nkrumah, J. D., E. K. Okine, G. W. Mathison, K. Schmid, C. Li, J. A. Basarab, M. A. Price, Z. Wang and S. S. Moore. 2006. Relationships of feedlot feed efficiency, performance, and feeding behavior with metabolic rate, methane production, and energy partitioning in beef cattle. J. Anim. Sci. 84:145-153.

Nkrumah, J. D., D. H. Keisler, D. H. Crews, Jr., J. A. Basarab, Z. Wang, C. Li, M. A. Price, E. K. Okine and S. S. Moore. 2007a. Genetic and phenotypic relationships of serum leptin concentration with performance, efficiency of gain, and carcass merit of feedlot cattle. J. Anim. Sci. 85:2147-2155.

Nkrumah, J. D., D. H. Crews Jr., J. A. Basarab, M. A. Price, E. K. Okine, Z. Wang, C. Li and S. S. Moore. 2007b. Genetic and phenotypic relationships of feeding behavior and temperament with performance, feed efficiency, ultrasound, and carcass merit of beef cattle. J. Anim. Sci. 85:2382-2390.

Nkrumah, J. D., J. A. Basarab, Z. Wang, C. Li, M. A. Price, E. K. Okine, D. H. Crews Jr. and S. S. Moore. 2007c. Genetic and phenotypic relationships of feed intake and different measures of feed efficiency with growth and carcass merit of beef cattle. J. Anim. Sci. 85:2711-2720.

Oddy, V. H. 1999. Genetic variation in protein metabolism and implications for variation in efficiency of growth. Rec. Adv. Anim. Nutr. Aust. 12:23-29.

Okine, E. K., Basarab, J., Baron, V. and Price, M. A. 2001. Net feed efficiency in young growing cattle: III Relationship to methane and manure production. In Abstracts of Presentations and Posters, Agricultural Institute of Canada, 2001 Conference, University of Guelph, Guelph, ON. Vol. 16.

Rayburn, E. and J. Lozier. 2003. A falling plate meter for estimating pasture forage mass. West Virginia University Cooperative Extension Service. Morgantown. 
Remesy, C. and C. Demigne. 1974. Determination of volatile fatty acids in plasma after ethanolic extraction. Biochem. J. 141:85-91.

Reynolds, C. K., H. F. Tyrell and L. E. Armentano. 1992. Effects of mesenteric vein nButyrate infusion on liver metabolism by beef steers. J. Anim. Sci. 70:2250-2261.

Richardson, E. C., R. J. Kilgour, J. A. Archer, and R. M. Herd. 1999. Pedometers measure differences in activity in bulls selected for high or low net feed efficiency. Proc. Aust. Soc. Study Anim. Behav. 26:16. (Abstr.)

Richardson, E. C., R. M. Herd, V. H. Oddy, J. M. Thompson, J. A. Archer and P. F. Arthur. 2001. Body composition and implications for heat production of Angus steer progeny of parents selected for and against residual feed intake. Aust. J. of Exp. Agr. 41:1065-1072.

Richardson, E. C., R. M. Herd, I. G. Colditz, J. A. Archer and P. F. Arthur. 2002. Blood cell profiles of steer progeny from parents selected for and against residual feed intake. Aust. J. of Exp. Agr. 42:901-908.

Richardson, E. C., and R. M. Herd. 2004. Biological basis for variation in residual feed intake in beef cattle. 2. Synthesis of results following divergent selection. Aust. J. of Exp. Agr. 44:41-440.

Robinson, D. L., and V. H. Oddy. 2004. Genetic parameters for feed efficiency, fatness, muscle area and feeding behaviour of feedlot finished beef cattle. Livest. Prod. Sci. 90:255-270.

Rolfe, K. M., W. M. Snelling, M. K. Nielsen, H. C. Freetly, C. L. Ferrell, and T. G. Jenkins. 2011. Genetic and phenotypic parameter estimates for feed intake and other traits in growing beef cattle, and opportunities for selection. J. Anim. Sci. 89:3452-3459.

Sadler, L. J., A. K. Johnson, S. M. Lonergan, D. Nettleton, and J. C. M. Dekkers. 2011. The effect of selection for residual feed intake on general behavioral activity and the occurrence of lesions in Yorkshire gilts. J. Anim. Sci. 89:258-266.

Schenkel, F. S., S. P. Miller and J. W. Wilton. 2004. Genetic parameters and breed differences for feed efficiency, growth, and body composition traits of young beef bulls. Can. J. Anim. Sci. 84:177-185.

Seal, C. J., and D. S. Parker. 2000. Influence of gastrointestinal metabolism on substrate supply to the liver. Pages 131-148 in Ruminant Physiology, Digestion, Metabolism, Growth and Reproduction. P. B. Cronje, ed. CABI Publ., Wallingford, UK. 
Seal, C. J., and C. K. Reynolds. 1993. Nutritional implications of gastrointestinal and liver metabolism in ruminants. Nutr. Res. Rev. 6:185-208.

Shaffer, K. S. 2010. Residual feed intake, body composition, and fertility in yearling beef heifers. Master Thesis. West Virginia University.

Shaffer, K. S., P. Turk, W. R. Wagner, and E. E. D. Felton. 2011. Residual feed intake, body composition, and fertility in yearling beef heifers. J. Anim. Sci. 89:10281034.

Sharifabadi, H. Rajaei, M. J. Zamiri, E. Rowghani, and W. G. Bottje. 2012. Relationship between the activity of mitochondrial respiratory chain complexes and feed efficiency in fat-tailed Ghezel lambs. J. Anim. Sci. doi:10.2527/jas.2011-4791.

Smith, R. M., N. K. Gabler, J. M. Young, W. Cai, N. J. Boddicker, M. J. Anderson, E. Huff-Lonergan, J. C. M. Dekkers, and S. M. Lonergan. 2011. Effects of selection for decreased residual feed intake on composition and quality of fresh pork. J. Anim. Sci. 89:192-200.

Stick, D. A., M. E. Davis, S. C. Loerch and R. C. Simmen. 1998. Relationship between blood serum insulin-like growth factor I concentration and postweaning feed efficiency of crossbred cattle at three levels of dietary intake. J. Anim. Sci. 76:498-505.

Suzuki, E. Y. and R. J. Early. 1991. Analysis of chromic oxide in small samples of feeds and feces using chlorine bleach. Can. J. Anim. Sci. 71:931-934.

Uden, P., P. E. Colucci and P. J. Van Soest. 1980. Investigation of chromium, cerium and cobalt as markers in digesta rate of passage studies. J. Sci. Food Agric. 31:625.

United States Department of Agriculture-National Agriculture Statistics Service. January 2012 Cattle Inventory. 2012.

United States Department of Agriculture-National Agriculture Statistics Service. Farm production expenditures 2010 summary. August, 2011.

Varga, G. A., and E. C. Prigge. 1982. Influence of forage species and level of intake on ruminal turnover rates. J. Anim. Sci. 55:1498-1504.

Wang, Z., J. A. Basarab, L. A. Goonewardene, D. H. Crews, Jr., P. Ramsey, K. L. Lyle, N. French, E. K. Okine and S. S. Moore. 2005. Test duration for residual feed intake in commercial bulls. J. Anim. Vet Adv. 4:825-830.

Wang, Z., J. D. Nkrumah, C. Li, J. A. Basarab, L. A. Goonewardene, E. K. Okine. D. H. Crews, Jr. and S. S. Moore. 2006. Test duration for growth, feed intake, and feed efficiency in beef cattle using the GrowSafe System. J. Anim. Sci. 84:2289-2298. 
Young, J. M., W. Cai and J. C. M. Dekkers. 2011. Effect of selection for residual feed intake on feeding behavior and daily feed intake patterns in Yorkshire swine. J. Anim. Sci. 89:639-647. 


\section{VITA}

Name Kevin Scott Shaffer

Birthplace Philippi, WV

Date of Birth January 22, 1986

Parents John R. Shaffer .Nancy L. Shaffer

Schools Attended:

Philip Barbour High School 2000-2004 Philippi, WV

West Virginia University 2004-2007 Morgantown, WV

West Virginia University 2007-2010 Morgantown, WV

Degrees Received:

Bachelor of Science in Animal and Veterinary Science West Virginia University, 2007

Master of Science in Animal and Nutritional Science West Virginia University, 2010 


\title{
IDENTIFYING POTENTIAL SOURCES OF VARITION IN RESIDUAL FEED INTAKE IN BEEF CATTLE
}

\author{
Kevin S. Shaffer
}

\author{
Dissertation submitted to the \\ Davis College of Agriculture, Natural Resources, and Design \\ at West Virginia University \\ in partial fulfillment of the requirements \\ for the degree of \\ Doctor of Philosophy \\ in \\ Animal and Food Science \\ Department of Animal and Nutritional Science \\ APPROVAL OF THE EXAMINING COMMITTEE
}

Eugene E. D. Felton, Ph.D., Chair

Kimberly M. Barnes, Ph.D.

William B. Bryan, Ph.D.

E. Keith Inskeep, Ph.D.

Date

Wayne R. Wagner, Ph.D. 